\title{
Experimental Research and Numerical Simulation of Ejector Precipitator in a Fully Mechanized Mining Face
}

\author{
Guodong Zhai ${ }^{1}\left(\mathbb{D} \cdot\right.$ Wentao Zhang ${ }^{1} \cdot$ Yaozong $\mathrm{Li}^{2} \cdot$ Xinghao $\mathrm{Lu}^{1} \cdot$ Wenyuan $\mathrm{Hu}^{1}$
}

Received: 20 February 2020 / Accepted: 1 September 2020 / Published online: 7 October 2020

(c) The Author(s) 2020

\begin{abstract}
In order to effectively reduce the coal dust concentration in a fully mechanized mining face, this research used laboratory experiment, numerical simulation, and field test to conduct an in-depth exploration of the ejector precipitator installed at the low-level caving coal hydraulic support. Firstly, through the experimental platform in the laboratory, the dust removal effect of the nozzle with different structural parameters was tested, and the 3D particle dynamic analyzer was adopted to verify its atomization characteristics; then, the structural parameters corresponding to the nozzle in the best test results were obtained. Secondly, by using Fluent, the negative pressure flow field in the ejector barrel was numerically simulated. The results indicated that when the pressure of supply water was $12 \mathrm{MPa}$, the negative pressure value formed in the flow field was the lowest and the inspiratory velocity was the largest, which was conducive to dust removal. Finally, the tests of liquid-gas ratio and dust removal ratio were carried out in a fully mechanized mining face. The results showed that when the nozzle specification recommended by the experiment and the pressure of supply water recommended by the numerical simulation were used, the removal ratios of the total coal dust and the respirable coal dust were $89.5 \%$ and $91.0 \%$, respectively, at the measuring point of the highest coal dust concentration. It indicates that the ejector precipitator has a good application effect in reducing the coal dust concentration in a fully mechanized mining face and improving the work environment of coal mine workers.
\end{abstract}

Keywords Ejector precipitator $\cdot$ Nozzle $\cdot$ Atomization characteristics $\cdot$ Numerical simulation $\cdot$ Field test $\cdot$ Dust removal ratio

\section{Introduction}

At present, workplace pollution has become an important scientific research topic, which is of vital significance to the health of workers. Specifically, coal dust is one of the worst polluted disasters in the process of coal cutting [1-3]. If no dust removal strategy is adopted, the concentration of the coal dust can rise to $8000-10,000 \mathrm{mg} / \mathrm{m}^{3}$ in a fully mechanized mining face, which has caused irreparable harm to the physical and mental health of the coal miner [4-6]. According to the statistics released by the relevant departments, the occupational pneumoconiosis accounts for a very large pro-

Guodong Zhai

zgd@cumtb.edu.cn

1 School of Mechanical Electronic \& Information Engineering, China University of Mining and Technology-Beijing, Ding No. 11 Xueyuan Road, Haidian District, Beijing 100083, China

2 Zhengzhou Yutong Bus Co., Ltd., Zhengzhou 450018, China portion of various occupational diseases, and there are tens of thousands of new cases of occupational pneumoconiosis in China every year, greater than $80 \%$ of which are coal workers' pneumoconiosis and silicosis cases, which can be life-threatening in its most severe form [7-12]. Therefore, it is extremely significant to develop a set of dust removal equipment suitable for a fully mechanized mining face and to explore the critical factors affecting its dust removal ratio.

In order to valid control the pollution degree of coal dust, some dust removal strategies including coal-seam water injection, dust removal with chemical reagents, dust removal by ventilation, bubble scrubbing, and spray dust removal are adopted; the spray dust removal has many incomparable advantages including strong operability, low failure rate, and low cost and is frequently used in coal mine site at present [13-18]. Currently, the researches of spray dust removal technology by researchers are centered on two aspects, i.e., experimental study on atomization characteristics of nozzle spray and numerical simulation of multiphase flow coupling in the spray field. As for the experimental study on atomiza- 
tion characteristics of nozzle spray, Kou et al. [19] developed a new wind-spray precipitator based on rotary atomization. The rules between atomization efficiency and structure parameters such as rotating speed were obtained by experiments. The results revealed that the atomization efficiency reached above $95 \%$ under the optimal parameter conditions. Nie et al. [20] measured atomization characteristic indexes of nozzles including droplet diameter, spraying angle, and spraying range in the experiment, and then obtained the nozzle with the best atomization effect. The results showed that the spray from nozzles can settle the coal dust between the hydraulic supports. Cheng et al. [21] experimentally investigated the relationship between spray pressure and atomization parameters including injection angle, injection area, and droplet diameter. It was found that the dust suppression rate could rise above $70 \%$ under optimum pressure. Based on contrast experiment and orthogonal experiment, a new negative pressure secondary precipitator was developed by Sun et al. [22]. Moreover, they suggested a local spray strategy. The results showed that compared with the original dust removal strategy, the dust suppression rate of the new strategy increased by $44.3 \%$. Zhou et al. [23] studied the effects of spray pressure and nozzle structure on atomization characteristics from multiple aspects through the experiment and developed a new type of distribution equipment with double nozzles. Wang et al. [24] measured the atomization characteristics of the solid-cone spray by using a phase Doppler measuring instrument. This study revealed that the average size of the droplet is relatively stable and the velocity is faster in the short-range spraying range. Wang et al. [25] explored the atomization characteristics of the wind-assisted atomizing nozzle under different structural parameters, and further obtained the law of dust suppression efficiency varying with structural parameters through experiments. As for the simulation of multiphase flow coupling in the spray field, Nie et al. [26] numerically simulated the wind-fog two-phase flow field, and then obtained the law of the wind flow migration inside the precipitator, which provided a reference for the further study of the mechanism of spray dust removal. Yu et al. [27] established a mathematical model of the interaction among airflow, droplet, and coal dust. The migration behavior of coal dust with airflow and the migration process of the coupling field of the droplet and airflow were numerically simulated in this study, which verified the rationality of the established multiphase flow coupling model. Peng et al. [28] designed a new wind-assisted centralized spray precipitator and conducted a numerical simulation of the droplet concentration distribution in the spray field, and then obtained the most appropriate spraying parameters. The results showed that the removal ratio of the coal dust reached $87.96 \%$. Combined with computational fluid dynamics and discrete phase model, Zhou et al. [29] carried out numerical simulation of airflow migration and coal dust diffusion in the vicinity of advance support, and then designed a precipitator for coal dust generated in support movement.

Although the researchers cited above have conducted in-depth studies concerning the spray dust removal technology, owing to variable and unstable site conditions of a fully mechanized mining face, the existing researches are still insufficient. In terms of experiments, researchers mainly investigated the performance of spray precipitator using atomization parameters including spray angle, effective spray distance, and droplet size, while ignoring the evaluation of spray precipitator performance by macroparameters such as wind speed, water consumption, and liquid-gas ratio. In terms of numerical simulations, the researchers mainly conducted studies on coal dust migration with airflow and droplet-dust coupling, while the influence of the pressure of supply water on the characteristic distribution of a negative pressure flow field near the nozzle is rarely reported. Additionally, the droplets ejected by an inner-rotation nozzle have a high velocity and a large contact area with air, and the dust collection efficiency is high, but there is a lack of studies on the inner-rotation nozzles for field application. Generally, the high concentration of coal dust mainly comes from rolling-cut of the coal cutter and movement of the hydraulic support [30], so common spraying methods include coal caving spray, internal spray of coal cutter, external spray of coal cutter, hydraulic support spray, etc. However, during the operation of the coal cutter, with the cutting head continuously breaking the rock, the nozzle of the ejector precipitator is easily blocked, which severely limits its dust removal performance. The shield beam of the low-level caving coal hydraulic support is the closest to the position of coal caving and has a large space, which is especially suitable for the installation, dismantling, and maintenance of the ejector precipitator. Consequently, it is a better choice to arrange the ejector precipitator on the hydraulic support in a fully mechanized mining face.

In summary, the ejector precipitator installed at the lowlevel caving coal hydraulic support is taken as the research object, and the purpose of this study is to improve the coal dust removal ratio in a fully mechanized mining face. First, laboratory experiments are conducted to select suitable nozzle structure parameters. Then, numerical simulations are performed to give the appropriate pressure of supply water. Finally, field tests at a coal mine are carried out, and achieve a good application effect.

The remainder of paper is organized as follows. Section 2 introduces the working principle and the suitable installation position of the ejector precipitator. Section 3 introduces the testing scheme and results of macro and micro parameters. Section 4 introduces the basic preparation before numerical simulations, including the construction of a mathematical model, the completion of mesh generation, and the determination of boundary conditions. Section 5 introduces the 




Fig. 1 Working principle of the ejector precipitator

numerical simulation results of a negative pressure flow field and discussions. Section 6 introduces the field tests in a fully mechanized mining face. Finally, the conclusion is given in Sect. 7.

\section{Working Principle and Installation Position of the Ejector Precipitator}

\subsection{Working Principle of the Ejector Precipitator}

The ejector precipitator is composed of airflow collector, water spraying equipment, ejector barrel, and baffle separator [31], as shown in Fig. 1. When water pressurized by the underground pump station is transported to the water spraying equipment through pipes, a great deal of velocity energy is generated at the nozzle, and a high-speed atomized water jet is formed during spraying, thus creating a negative pressure area near the nozzle. At the same time, owing to the presence of the atomization angle, the water jet covered the entire ejector barrel in a cone mist shape and advanced at a high speed, forming a piston effect, and then generating a secondary negative pressure. Under the action of differential pressure, the dust-laden airflow is sucked in from the airflow collector, and its velocity will increase when it passes through the reduced section because the airflow collector is in a contracting shape. In the process of the dust-laden airflow moving forward in the ejector barrel, the coarse coal dust settles under the action of gravity and inertial collision, while fine coal dust is captured by water mist and pushed forward at high speed. Under the action of the baffle separator, the treated airflow and the dust-laden water are discharged from the upper and lower part of the baffle separator, respectively.

It should be noted that the spray dust removal mechanism proposed is different from the original Venturi negative pressure dust removal mechanism and wind-spray dust removal mechanism. For the original Venturi negative pressure dust removal mechanism, it is based on the Venturi effect and relies on negative pressure to suck up the surrounding airflow. Energy and mass transfer between airflow and droplet occurs in a Venturi device, which enhances the entrapment capacity of the negative pressure flow field [32]. For instance, a dust remover based on the Venturi negative pressure effect was designed by Ren et al. [33], its atomization nozzle had high requirements for the quality of liquid flow and airflow, otherwise the nozzle was prone to blockage. Usually, it is difficult to achieve complete atomization with a single negative pressure-based Venturi device. The nozzle used in the ejector precipitator in this study is designed with swirling and diversion structures. These structures cause the microfluidic unit to generate different velocity vectors, and then, the inertial force can be used to break the jet more thoroughly, which improves atomization efficiency. For the wind-spray dust removal mechanism, it usually adopts a wind-assisted atomizer nozzle to achieve atomization though the friction and collision between airflow and liquid [34]. Generally, wind velocity plays the most significant role among all relevant factors in wind-spray. For instance, research results of wind-assisted atomizer nozzle by Wang et al. [5] indicated that as the wind supply pressure increased, the primary atomization of the liquid was more sufficient, and the rate ratio of airflow to liquid flow increases greatly. Study results by Yin et al. [35] revealed that the droplet concentration and coverage area of spraying were significantly increased when the external spray device of the coal cutter was equipped with fans. Accordingly, the atomization efficiency of windspray can reach the highest when there is a suitable wind supply pressure and wind-liquid ratio. Although wind-spray has better atomization ability and improves atomization efficiency, compared with the spray scheme proposed in this study, its utilization is limited by the difficulty in adjusting the pressure-supply ratios of wind and liquid in the nozzle and the difficulty in maintaining.

\subsection{Installation Position of the Ejector Precipitator}

The ejector precipitator designed in this research is mainly aimed at the coal dust produced by the coal drawing mouth of the shield beam of the low-level caving hydraulic support. There is plenty of room under the shield beam, few pipelines, no control valve, and close to the coal discharge position, so the ejector precipitator is installed under the shield beam. As shown in Fig. 2, the ejector precipitator is welded to the shield beam through the lifting lug, at this point, the central axis of the ejector barrel is parallel to the coal discharge working face, which is conducive to work of the ejector precipitator.

\section{Experimental Platform and Scheme for Selection of Nozzles}

The nozzle is a key component of the ejector precipitator, and its structural parameters have a direct influence on the performance of the ejector precipitator [26]. Since the 


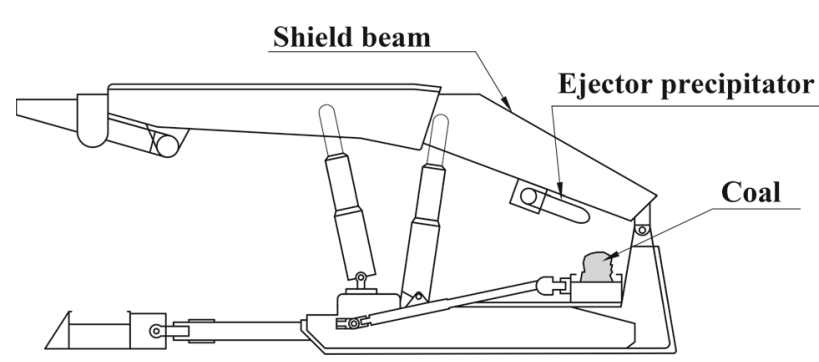

Fig. 2 Installation position of the ejector precipitator

ejector precipitator designed in this study has the characteristics of both negative pressure aspiration and atomizing dust capture, the macroscopic indicators of its performance are wind speed, water consumption, and liquid-gas ratio; the microscopic indicators are droplet diameter and velocity. Obviously, it is convenient and effective to obtain these indicator data through a testing platform. This experiment was carried out in two steps. In the first step, wind speed at the inlet end and water consumption of an ejector precipitator were measured under the combination of different nozzle structure parameters. In the second step, by testing the atomization characteristics of the nozzle, the diameter distribution and velocity distribution of the spray from the selected nozzle in the first step were verified to see whether it can meet the practical requirements with the micro-parameter test platform.

\subsection{Structure and Size of the Nozzle}

The nozzle used in this study was the inner-rotation nozzle, which was assembled by the outer shell and the rotating core, as shown in Fig. 3. $D_{0}$ represents the exit-hole diameter of the outer shell, $T$ represents the exit length of the outer shell, $\alpha$ represents the cone angle at exit of the outer shell, $\beta$ represents the intracavity angle of the outer shell, $d$ represents the through-hole diameter of the rotating core, $L_{1}$ represents the spiral grooves spacing of the rotating core, and $L_{2}$ represents the spiral grooves width of the rotating core. The center of the core was provided with a through-hole, and the periphery of the core was provided with many pairs of the
Table 1 The structural parameters of the outer shell

\begin{tabular}{lllllll}
\hline Number of the outer nozzle & 1 & 2 & 3 & 4 & 5 & 6 \\
\hline$D_{0}(\mathrm{~mm})$ & 1.0 & 1.0 & 1.5 & 2.0 & 1.5 & 2.5 \\
$T(\mathrm{~mm})$ & 1.5 & 1.0 & 0.5 & 1.5 & 1.0 & 1.0 \\
$\alpha\left(^{\circ}\right)$ & 180 & & & & & \\
$\beta\left({ }^{\circ}\right)$ & 120 & & & & & \\
\hline
\end{tabular}

spiral grooves. When the water reached the nozzle, it created multiple streams of water, one of which advanced along the through-hole of the rotating core and the rest rotated along the spiral grooves. Finally, multiple streams of water converged at the outlet of the nozzle and sprayed out, forming a cone-shaped water mist [36].

After investigating the major nozzle manufacturers on the market and the application situation of nozzles in coal mine dust removal site, and comprehensively considering the installation, disassembly, and processing factors of the nozzle, the structural parameters shown in Tables 1 and 2 were selected for measurement. Six types of the outer shells and 10 types of the rotating cores were used in this experiment, and the outer shell and the rotating core were calibrated and distinguished by Arabic numerals. It should be noted that the variable structural parameters were $D_{0}, T, d, L_{1}, L_{2}$ and the number of the spiral grooves, the fixed structural parameters were $\alpha$ and $\beta$, and the shape of the spiral grooves was rectangular.

\subsection{Measurement of Macroscopic Parameters}

\subsubsection{Design of Experimental Platform}

The purpose of the macro-parameter test platform is to explore the influence of the nozzle's structural parameters on the wind speed at the inlet end and the volume of water usage. As shown in Fig. 4, during the experiment, when water-service installation was turned on, the water entered the water inlet pipe and the flowmeter from the water source, at this point, the motor and the high-pressure pump were started, and the water was pressurized. The pressurized water



(a) Structure of the nozzle

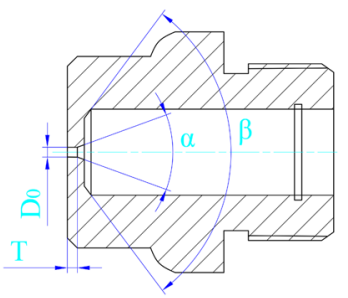

(b) Structure of the outer shell

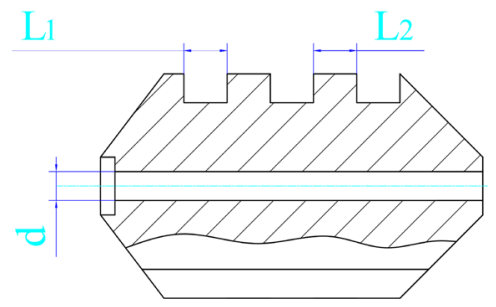

(c) Structure of the rotating core

Fig. 3 Structure of the nozzle, where a structure of the nozzle, $\mathbf{b}$ structure of the outer shell, $\mathbf{c}$ structure of the rotating core 
Table 2 The structural parameters of the rotating core

\begin{tabular}{lllllllllll}
\hline Number of rotating core & 1 & 2 & 3 & 4 & 5 & 6 & 7 & 8 & 9 & 10 \\
\hline Number of the spiral grooves & 4 & 4 & 4 & 4 & 4 & 4 & 3 & 2 & 2 & 2 \\
$d(\mathrm{~mm})$ & 1.5 & 1.5 & 1.5 & 1.5 & 1.2 & 1.0 & 1.5 & 1.5 & 1.5 & 1.5 \\
$L_{1}(\mathrm{~mm})$ & 1.2 & 1.1 & 1.0 & 1.5 & 1.5 & 1.2 & 1.2 & 2.0 & 1.0 & 1.2 \\
$L_{2}(\mathrm{~mm})$ & 1.8 & 1.8 & 2.0 & 1.8 & 1.0 & 1.8 & 1.8 & 2.0 & 2.0 & 1.5 \\
\hline
\end{tabular}

Fig. 4 The macro-parameter test platform



passed through the pressure gauge and high-pressure water pipe to the nozzle and started spraying. Then the Pitot tube and U-shaped tube pressure gauge were applied to measure the wind speed at the intake end of the ejector precipitator, and the water consumption was read by the flowmeter. It should be noted that all experimental data were recorded in detail and accurately by specially assigned persons throughout the experiment.

The purpose of this experiment is to discuss the influence of the nozzle's structural parameters, so the preliminary parameter experiments were carried out. The preliminary tests were made on different pressure of supply water values and the positions of the nozzles in the ejector barrel by using the single variable method, pressure of supply water in subsequent experiments was determined to be $12 \mathrm{MPa}$, the nozzle was mounted on the central axis of the ejector barrel and $250 \mathrm{~mm}$ away from the inlet of the ejector barrel. Besides, the ejector barrel was $900 \mathrm{~mm}$ in length and $102 \mathrm{~mm}$ in diameter.

\subsubsection{Results and Discussion}

The uncertainty of experimental data should be considered because there were uncertainty factors in measuring equipment and environment. The uncertainty component of experimental data mainly came from the measurement uncertainty of the flowmeter, the Pitot tube, and the U-shaped tube pressure gauge. For the flowmeter, its accuracy level was level 1 , and the uncertainty of the indication error within the $95 \%$ confidence interval was $0.25 \%$, so measurement uncertainty of the flow was very small. For the Pitot tube, it had a maximum allowable error of $0.3 \%$, and the measurement uncertainty of wind speed introduced by repeated measurement was also small. For the U-shaped tube pressure gauge, its work was stable and the measurement repeatability was good, so the measurement uncertainty introduced was negligible. Additionally, due to the small changes of hydraulic and thermal conditions in the high-pressure pipe, the standard uncertainty caused in terms of expansion coefficient, outflow coefficient, and temperature could also be ignored. Finally, considering the existence of gross error, the abnormal data in experiments were discarded, which further improved the confidence of experimental data.

The acquired data was imported into Origin2020 for statistics and analysis. The variations of wind speed and water consumption under different combinations of structural parameters are shown in Fig. 5, and the different colors of the legend in the figure represent the number of the outer shell.

It can be observed in Fig. 5 that:

1 The wind speed value measured after the outer shell 5 was matched with each the rotating core was generally larger, and the wind speed measured when the outer shell 5 was matched with the rotating core 6 and the rotating core 7 was the largest, which were $115.3 \mathrm{~m} / \mathrm{s}$ and $117.1 \mathrm{~m} / \mathrm{s}$, respectively, and the water consumption was $11.2 \mathrm{~L} / \mathrm{min}$ and $10.6 \mathrm{~L} / \mathrm{min}$, respectively. The water consumption measured when the outer shell 6 and the rotating core 5 were matched was the smallest, which was 4.6 $\mathrm{L} / \mathrm{min}$, and the wind speed was $60.8 \mathrm{~m} / \mathrm{s}$. 


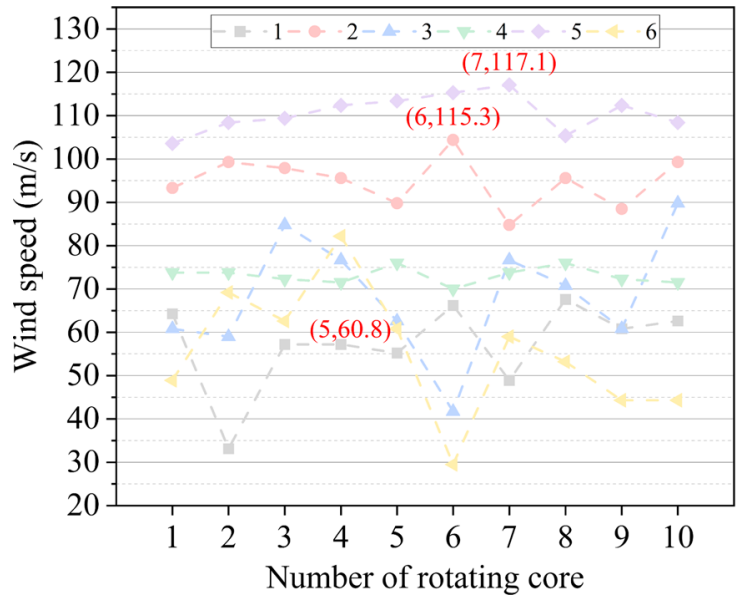

(a) The variations of wind speed

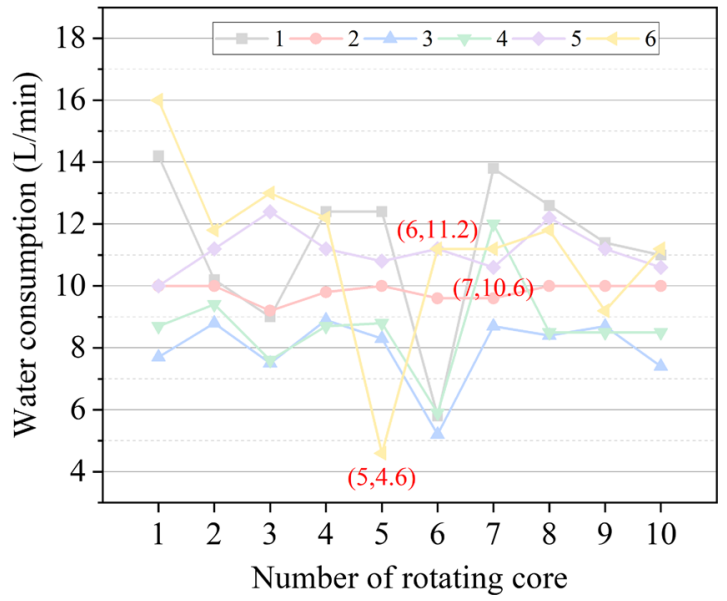

(b) The variations of water consumption

Fig. 5 The variations of wind speed and water consumption, where a the variations of wind speed, $\mathbf{b}$ the variations of water consumption

2 Generally, maximum wind speed and minimum water consumption are the best results. To comprehensively consider the indicator data of wind speed and water consumption, it is necessary to calculate the liquid-gas ratio, which is defined as the ratio of water consumed to air inflow. Normally, the smaller the liquid-gas ratio, the better. As a result, the liquid-gas ratio was the smallest when the outer shell 5 was matched with the rotating core 6 by calculation, which was is 1: 5047 .

To further determine the shape of the rotating core, the shape and number of the spiral grooves of core 6 and core 7 were changed, and then matched with the outer shell 5 to carry out the experimental measurement. The matching situation is shown in Table 3; based on the original number, the rotating cores of different specifications were represented by letter codes. The experimental results of wind speed and water consumption are shown in Fig. 6.

It is found in Fig. 6 that:

1 The wind speed and water consumption corresponding to the $\mathrm{H}$ rotating core were the lowest. Generally, the performance of an inner-rotation nozzle is affected by the number and cross-sectional shape of the spiral grooves. When the liquid flows along spiral grooves, it will be subjected to the action of rotating centrifugal force, thereby forming multiple filamentary jets. At the nozzle outlet, a vortex is formed after friction between the jet and the surrounding air, thus sucking up the dusty airflow. For $\mathrm{H}$ rotating core, the number of the spiral grooves was 2 and the shape of the spiral grooves was triangle, which not only reduced the amount of liquid flow entering, but

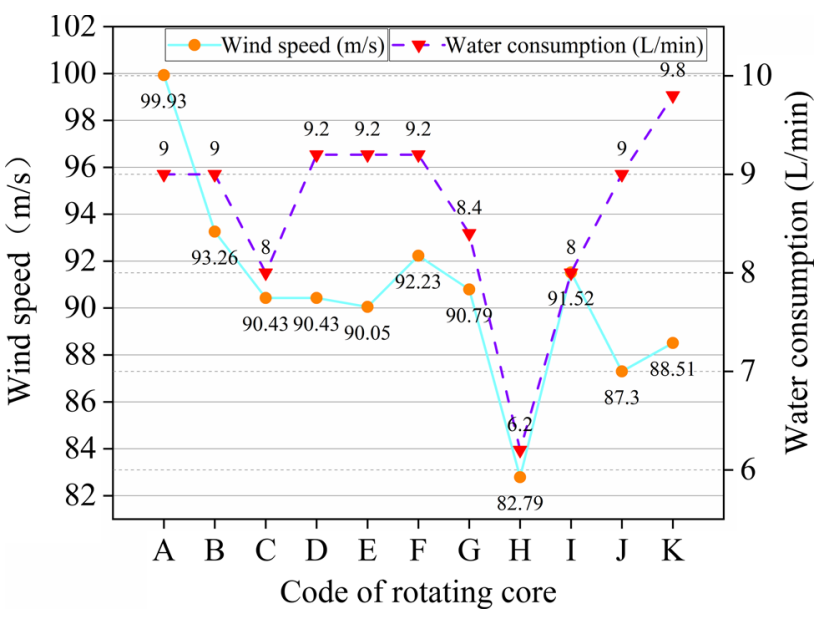

Fig. 6 The experimental results of wind speed and water consumption

also weakened the turbulence degree of liquid flow and reduced the vortex intensity near the nozzle outlet, so the wind speed and water consumption were reduced accordingly.

2 The wind speed corresponding to the core 6-a was the largest, which was $99.93 \mathrm{~m} / \mathrm{s}$, the water consumption was $9.0 \mathrm{~L} / \mathrm{min}$, and its liquid-gas ratio was the smallest.

In summary, when using the inner-rotation nozzle to remove dust at the mining site, it is recommended that the structural parameters of the outer shell are as follows: $D_{0}=$ $1.5 \mathrm{~mm}, T=1.0 \mathrm{~mm}$; the structure parameters of rotating core are as follows: $d=1.0 \mathrm{~mm}, L_{1}=1.2 \mathrm{~mm}$, and $L_{2}=$ $1.8 \mathrm{~mm}$; besides, the shape of the spiral grooves is rectangular and the number of the spiral grooves is 3 . 
Table 3 Combination of the outer shell and rotating core

\begin{tabular}{lllll}
\hline $\begin{array}{l}\text { Number of the outer } \\
\text { shell }\end{array}$ & $\begin{array}{l}\text { Number of the } \\
\text { rotating core }\end{array}$ & Letter code & $\begin{array}{l}\text { Number of the spiral } \\
\text { grooves }\end{array}$ & $\begin{array}{l}\text { Shape of the spiral } \\
\text { grooves }\end{array}$ \\
\hline 5 & 6 & A & 3 & Rectangle \\
6 & B & 2 & Rectangle \\
7 & C & 2 & Rectangle \\
7 & D & 2 & Circular \\
7 & E & 3 & Circular \\
6 & F & 2 & Circular \\
6 & G & 3 & Circular \\
6 & H & 2 & Triangle \\
6 & I & 3 & Triangle \\
7 & J & 2 & Triangle \\
7 & K & 3 & Triangle \\
\hline
\end{tabular}

Fig. 7 The micro-parameter test platform

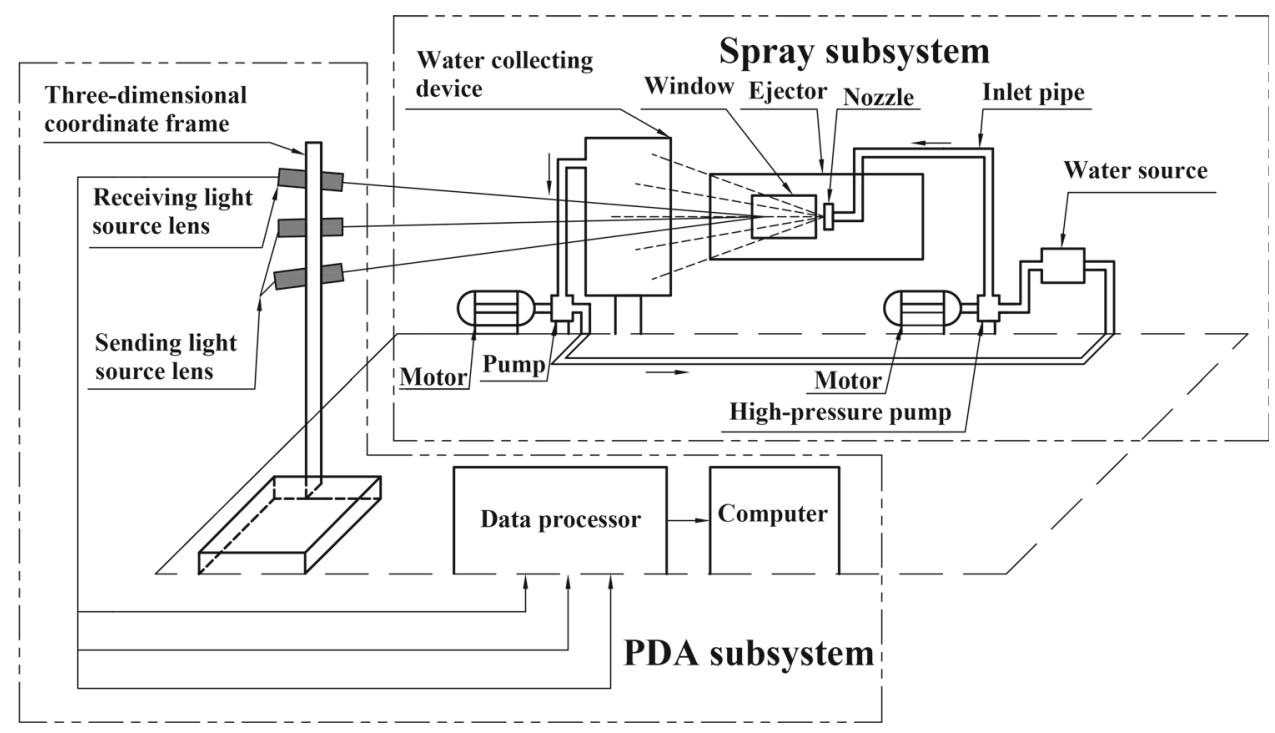

\subsection{Measurement of Microscopic Parameters}

From the microscopic point of view, the velocity distribution and diameter distribution of the spray injected from the nozzle will affect the trapping effect of the spray on coal dust, and then directly affect the dust removal ratio of the ejector precipitator. Generally, within the effective area from the nozzle, the average velocity of the spray is required to be greater than $20 \mathrm{~m} / \mathrm{s}$, and the average diameter of the spray is preferably in the range of $20 \mu \mathrm{m}$ to $50 \mu \mathrm{m}$.

\subsubsection{Design of Experimental Platform}

The micro-parameter test platform consisted of the spray system and the 3D particle dynamic analysis (PDA) system [36]. As shown in Fig. 7, firstly, the pressurized water from the high-pressure pump was emitted from the nozzle, and then, the PDA system emitted the laser and picked up a laser signal, which was transmitted to the data processor for analysis.
Finally, the values of the velocity and droplet diameter at the measured point can be obtained. It should be emphasized that the data of droplet diameter and velocity in the spray field during the experiment were automatically saved by the computer without manual recording. The test scene is shown in Fig. 8, the Danese company's PDA was used and it can satisfy all the requirements of measuring atomization characteristics of nozzles.

\subsubsection{Point Arrangement}

In the Cartesian coordinate system, let $X, Y$, and $Z$ be the three coordinate axes, and $U, V$, and $W$ be the corresponding velocity components of the spray on the $X, Y$, and $Z$ coordinate axes, respectively. The water mist was ejected along the $X$-axis. The measuring point was first moved along the $X$ axis and multiple sampling points were selected, and then, it was moved radially and multiple sampling points were selected. Generally, when the sampling time reached $2 \mathrm{~min}$ 


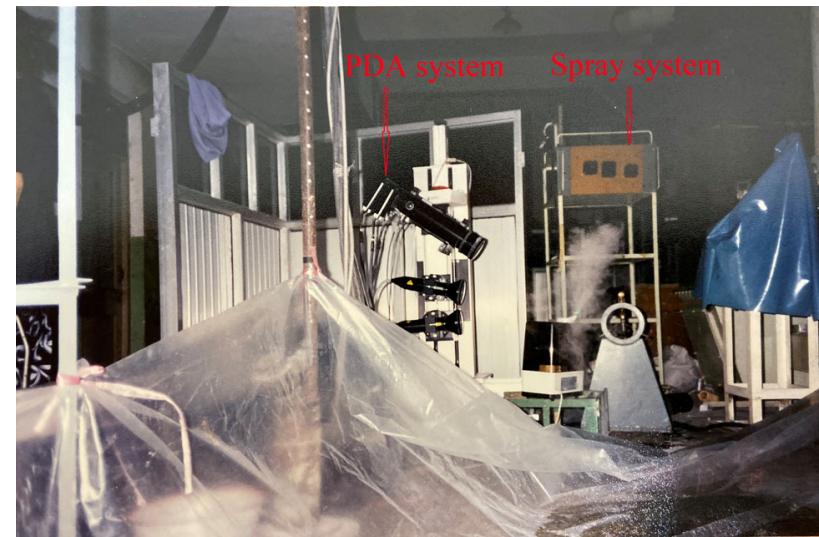

Fig. 8 The test scene for microcosmic parameters

or more than 3000 droplet samples were taken, the sampling operation ended.

\subsubsection{Results and Discussion}

The spray was measured when the pressure of supply water was $12 \mathrm{MPa}$. The standard uncertainty of measurement data was mainly affected by the PDA system. The speed measurement range of the PDA system was $0-500 \mathrm{~m} / \mathrm{s}$, with an accuracy of $1 \%$; the particle size measurement range was $0.5-10,000 \mu \mathrm{m}$, with an accuracy of $4 \%$. The laser in the PDA optical path was continuously adjustable, and its nonlinear error and repeatability error were very small. The data processing device in the PDA system had high performance and good stability, so the uncertainty introduced by the signal processing method could be ignored. Additionally, under PDA laboratory conditions, the uncertainty caused by environmental interference and signal-to-noise ratio was less than $0.05 \mathrm{~dB}$ in amplitude and less than $1^{\circ}$ in phase. Thusly, the standard uncertainty of data caused by the PDA system and the environment was very small, i.e., the confidence of the measured data could meet the requirements.

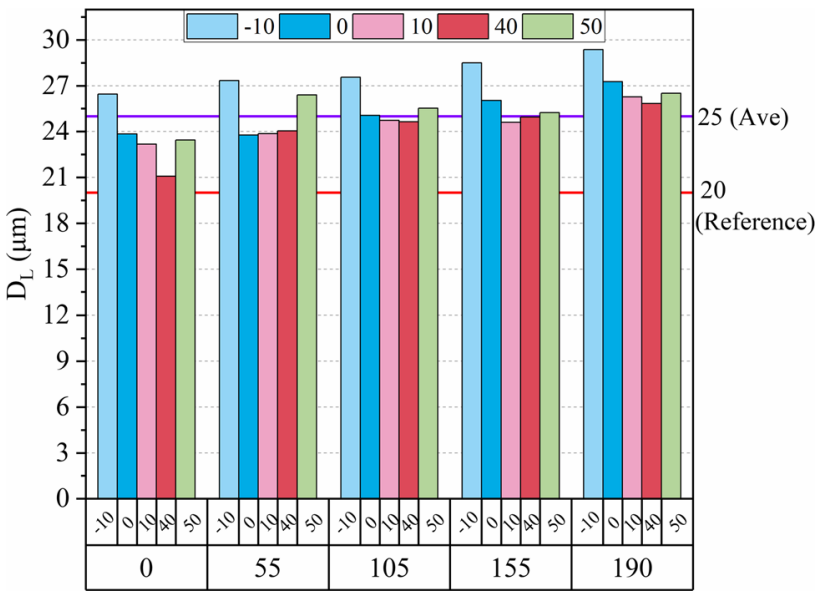

Fig. 10 The droplet diameter distribution in the three coordinate directions

The raw data obtained must be pre-processed with a conversion matrix. The PDA system came with data processing software SIZEware, and the processing module built in SIZEware could complete the data conversion. Subsequently, the new data was imported into Origin 2020 for statistics and analysis. The velocity distribution and diameter distribution of droplet at the sampling points are shown in Figs. 9 and 10 , the top column of the horizontal coordinate in the figure was the $Y$ measurement point, and the bottom column of the horizontal coordinate was the $X$ measurement point.

It is found in Fig. 9 that:

1 The value represented by the red horizontal line in the figure was the recommended reference value for the average spray velocity, which was generally taken as $20 \mathrm{~m} / \mathrm{s}$, and the value represented by the purple horizontal line was the average value of the actual spray velocity, with an average value of $29 \mathrm{~m} / \mathrm{s}$, therefore, the average value of the actual spray velocity was higher than the recommended velocity. Besides, it can be known that the velocity of the

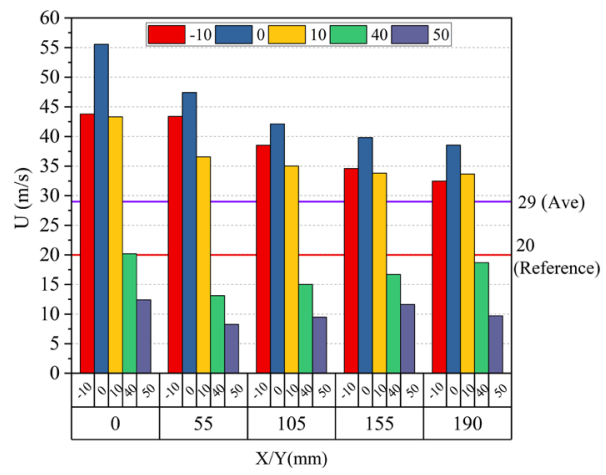

(a) U-velocity distribution

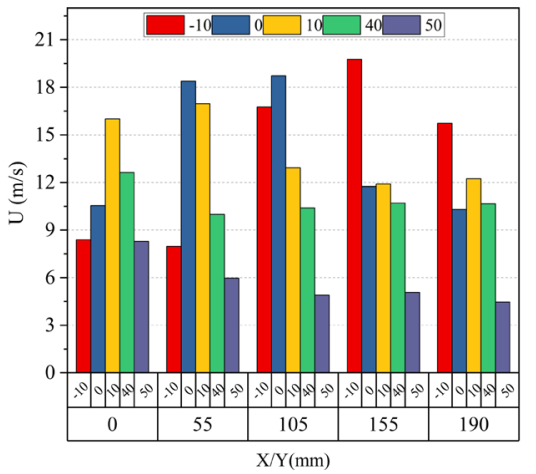

(b) V-velocity distribution



(c) W-velocity distribution

Fig. 9 The velocity distribution in the three coordinate directions, where a $U$-velocity distribution, $\mathbf{b} V$-velocity distribution, $\mathbf{c} W$-velocity distribution 
spray was the highest at the coordinate position of $Y=0$ (on the axis of the ejector barrel), which was all above the average. In general, the $U$-velocity in the $X$ orientation was larger when the liquid was just away from the nozzle, but as the spray distance increased, the $U$ gradually decreased, and when the spray reached a certain distance, the decline tended to be gentle.

2 It can be known that the change law of $V$ and $W$ was not obvious, because the spray was constrained by the ejector barrel wall in the orientation of $Y$ and $Z$ under the condition of finite space jet, and was affected by the friction force and radial pressure gradient.

It is found in Fig. 10 that:

1 The value represented by the red horizontal line was the recommended reference value of the average droplet diameter, which was generally $20 \mu \mathrm{m}$, and the value represented by the purple horizontal line was the average actual droplet diameter of the spray, which was $25 \mu \mathrm{m}$. It can be found that the average actual droplet diameter of the spray was larger than the recommended reference particle size, and in general, the fluctuation of particle size was small; it can indicate that the change of particle size tended to be smooth after the spray left the nozzle.

2 To sum up, the experimental results of the microparameter testing platform showed that the spray emitted from the nozzle with the outer shell 5 and the rotating core 6 met the general requirements in terms of velocity and droplet diameter within the effective range from the nozzle, so the experimental results of the macro-parameter testing platform were reasonable and effective.

\section{Basic Preparation for Numerical Simulations}

To deeply explore the effect mechanism of the pressure of supply water on the pressure and velocity distribution in the flow field, a negative pressure flow field in the ejector barrel was numerically simulated based on Fluent. This section mainly introduces the basic preparation before numerical simulations.

\subsection{Mathematical Model of a Negative Pressure Flow Field in the Ejector Barrel}

When the nozzle sprays high-speed water mist outward, due to the effect of the piston effect in an ejector barrel, a negative pressure flow field in which the liquid and gas coexist is formed. Namely, according to the jet atomization mechanism and entrainment characteristics, the main participants in the formation of the negative pressure flow field in the ejector barrel are liquid flow and airflow, so the mathematical model only considers gas-liquid two-phase flow.

Based on standard $k-\varepsilon$ model and VOF model, the numerical simulation for negative pressure flow field in the ejector barrel was carried out. Only the dynamic properties of the flow field are considered, not the thermodynamic properties, so the energy equation is omitted. The governing equations including the continuity equation and the kinetic equation of the fluid under the cartesian coordinate system can be written as [37-41]:

The continuity equation of the flow field:

$$
\frac{\partial}{\partial t}\left(\rho_{q} \alpha_{q}\right)+\frac{\partial}{\partial x_{j}}\left(\rho_{q} \alpha_{q} u_{q i}\right)=0
$$

The kinetic equation of the flow field:

$$
\frac{\partial}{\partial t}\left(\rho_{q} \alpha_{q} u_{q i}\right)+\frac{\partial}{\partial x_{j}}\left(\rho_{q} \alpha_{q} u_{q i} u_{q j}\right)=\frac{\partial}{\partial x_{j}}\left(\alpha_{q} \mu_{q} \frac{\partial u_{q i}}{\partial x_{j}}\right)+S_{q},
$$

where subscripts $q=1, \mathrm{~g}$, and 1 is liquid phase, $\mathrm{g}$ is gas phase; subscripts $i, j=1,2$, and 3 , respectively, represent the three different directions of the plane-coordinate system $X$, $Y$, and $Z ; \rho$ is the density of liquid, $\mathrm{kg} / \mathrm{m}^{3} ; \alpha$ denotes the volume fraction; $u$ denotes the fluid velocity, $\mathrm{m} / \mathrm{s} ; \mu$ denotes the dynamic viscosity, $\mathrm{N} \cdot \mathrm{s} / \mathrm{m}^{2} ; t$ denotes the time, $\mathrm{s} ; S_{q}$ denotes the source term.

At the two-phase interface, the balance equation of the mass and momentum can be expressed as:

$$
\left\{\begin{array}{l}
\sum_{q} \rho_{q}\left(u_{q}-u_{\mathrm{s}}\right) n=0 \\
\sum_{q}\left(\rho_{q}\left(u_{q}-u_{\mathrm{s}}\right) n+\sigma_{n} n\right)=F_{\mathrm{S}}
\end{array}\right.
$$

where $u_{\mathrm{s}}$ denotes the interface speed, $\mathrm{m} / \mathrm{s} ; F_{\mathrm{s}}$ denotes the interface forces per unit interface area, $\mathrm{N}$.

To close the governing equations of the flow field, it is necessary to introduce the turbulent kinetic energy $k$ and the dissipation velocity of the turbulent kinetic energy $\varepsilon$. Also, considering that the liquid and gas phases in an ejector barrel flow linearly and the Reynolds number is high, the standard $k-\varepsilon$ model is adopted. The transport equations based on the $k$ and the $\varepsilon$ can be expressed as [42-47]:

The $k$-equation:

$$
\frac{\partial(\rho k)}{\partial t}+\frac{\partial\left(\rho k u_{i}\right)}{\partial x_{i}}=\frac{\partial}{\partial x_{j}}\left[\left(\mu+\frac{\mu_{t}}{\sigma_{k}}\right) \frac{\partial k}{\partial x_{j}}\right]+G_{k}-\rho \varepsilon
$$

The $\varepsilon$-equation:

$$
\frac{\partial(\rho \varepsilon)}{\partial t}+\frac{\partial\left(\rho \varepsilon u_{i}\right)}{\partial x_{i}}=\frac{\partial}{\partial x_{j}}\left[\left(\mu+\frac{\mu_{t}}{\sigma_{\varepsilon}}\right) \frac{\partial \varepsilon}{\partial x_{j}}\right]+G_{1 \varepsilon} G_{k} \frac{\varepsilon}{k}-G_{2 \varepsilon} \rho \frac{\varepsilon^{2}}{k},
$$


Fig. 11 The smoothing quality

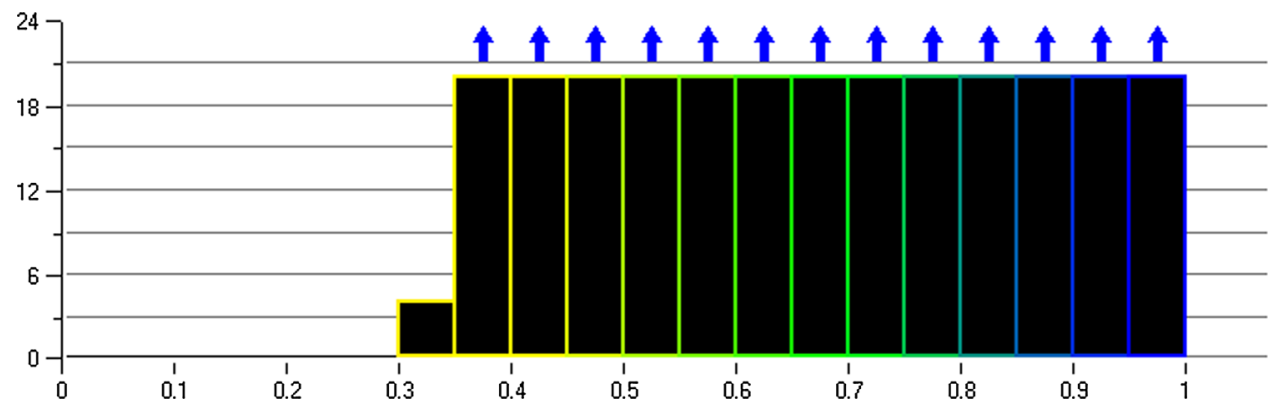

where $\mu_{\mathrm{t}}$ is viscosity coefficient of the turbulent flow, Pa.s; $G_{k}$ is generated items of the turbulent kinetic energy due to average velocity gradient, $\mathrm{kg} /\left(\mathrm{s}^{3} \cdot \mathrm{m}\right)$; The empirical values of $C_{1 \varepsilon}$ and $C_{2 \varepsilon}$ are 1.44 , and 1.92, respectively. $\sigma_{k}$ and $\sigma_{\varepsilon}$ are the Prandtl numbers of turbulent flow associated with $k$ and $\varepsilon$ equations, respectively, and the values are determined as $\sigma_{k}=1.0$ and $\sigma_{\varepsilon}=1.3$.

Where

$\rho=\alpha_{1} \rho_{\mathrm{l}}+\alpha_{\mathrm{g}} \rho_{\mathrm{g}}$

Since liquid and gas are incompatible with each other and share a set of governing equations, the VOF model is adopted in order to track the phase interface of each computing unit and assign variables to each control unit within a certain range. Each cell grid records the volume fraction occupied by each phase component in the cell during the iterative calculation, that is, each phase fluid in each control body has a corresponding volume rate, the volume rate of the same fluid in each control body forms a volume rate equation set. The volume rate equations for the $q$-phase fluid in the ejector barrel can be written as:

$$
\left\{\begin{aligned}
\frac{\partial \alpha_{q}}{\partial t}+u \cdot \operatorname{grad} \alpha_{q} & =0 \\
\alpha_{1}+\alpha_{\mathrm{g}} & =1
\end{aligned}\right.
$$

The above partial differential equations need to be solved numerically. First, they are discretized on the grid, and then, the gridlines divide the continuous computational domain into finite discrete points, that is, the partial differential equations are transformed into the algebraic equation on each node. Finally, the solutions are obtained by solving the algebraic equations directly. Generally, the solution of the discrete equation is maximized to approximate the exact solution of the corresponding partial differential equation when the grid nodes are closely spaced.

\subsection{Meshing and Finite Element Model}

According to a nozzle structure recommended by laboratory experiments, a physical model was loaded into ICEM.CFD

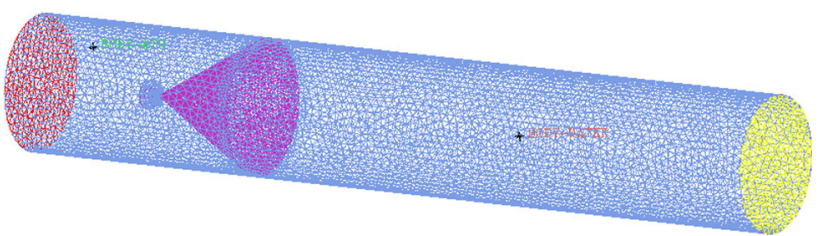

Fig. 12 The meshing effect

for meshing in an unstructured pattern. Since there were liquid domain and the airflow domain in the ejector barrel, in order to ensure the data transfer of the two calculation domains, the non-conformal interface needed to be built on the domain interface. According to the structure and installation of the nozzle in the ejection barrel, the interface was a conical surface with an angle of $60^{\circ}$ started from the outlet of the nozzle and ended with the ejection barrel wall. Considering that physical quantities changed significantly at the interface, local mesh encryption should be performed here to reduce the effect of numerical dissipation. The quality of mesh generation can directly affect the reliability and stability of numerical analysis [48], it was necessary to smooth it. The minimum default value for smoothing was 0.2 , and the closer to 1, the better the mesh quality. As shown in Fig. 11, the minimum value after the field smoothing was 0.3 . The results of numerical calculation showed that the grid quality was suitable for the current physical model, and it will increase the computational cost if the grid quality is further improved. The final meshing effect is shown in Fig. 12.

\subsection{Boundary Conditions and Spray Source Parameters}

The pressure-based solver was selected. As mentioned above, the standard $k-\varepsilon$ model and the VOF model were adopted. The liquid was set as the primary phase and the airflow as the second phase. The outlet of the nozzle was set as the pressure inlet, and its parameter values (pressure of supply water) were taken as the independent variable in the simulation. The inlet of the ejector barrel was set as the velocity inlet, and its parameter value was set as $3.7 \mathrm{~m} / \mathrm{s}$. The outlet of the ejector barrel was set as the pressure outlet, and its parameter value was set as one standard atmosphere. Let 

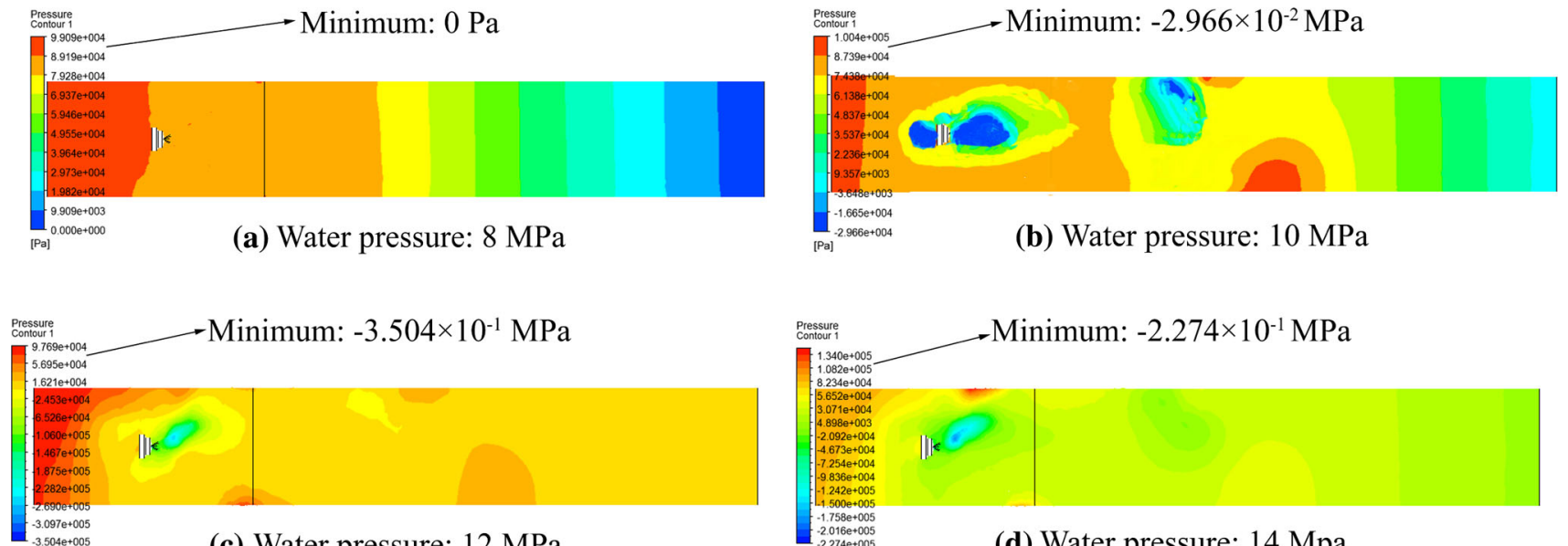

(c) Water pressure: $12 \mathrm{MPa}$

(d) Water pressure: $14 \mathrm{Mpa}$



Fig. 13 The pressure distribution on the central surface of the ejector barrel under different pressure of supply water, where a water pressure: $8 \mathrm{MPa}$, b water pressure: $10 \mathrm{MPa}$, c water pressure: $12 \mathrm{MPa}$, $\mathbf{d}$ water pressure: $14 \mathrm{MPa}$, e water pressure: $16 \mathrm{MPa}$

the interface between liquid and airflow be non-conformal interface, the spray source was the pressure-swirl atomizer, the number of particle flow was 500, and the spray material was water-liquid. The pressure simulation values were set to $8 \mathrm{MPa}, 10 \mathrm{MPa}, 12 \mathrm{MPa}, 14 \mathrm{MPa}$, and $16 \mathrm{MPa}$.

\section{Numerical Simulation Results and Discussion}

\subsection{Pressure Distribution and Discussion}

The pressure distribution on the central surface of the ejector barrel is shown in Fig. 13 under different pressure of supply water.

It can be observed in Fig. 13 that:

1 When the pressure of supply water was $8 \mathrm{MPa}$, the pressure in the ejector barrel gradually decreased from left to right, and the pressure gradient was uniform and it had the characteristics of up and down symmetry. There was no negative pressure zone near the nozzle, and the minimum pressure value in the flow field was $0 \mathrm{~Pa}$.

2 When the pressure of supply water was $10 \mathrm{MPa}$, the pressure gradient changed dramatically and the graph distribution of the same pressure gradient was irregular. A negative pressure zone appeared around the nozzle and somewhere of the pipe wall, the negative pressure at the nozzle was caused by a high-speed water jet. The negative pressure on the wall of the ejector barrel was caused by the change of the direction and size of the fluid velocity after the fluid collided with the wall in the process of moving forward. The minimum pressure in the flow field was - 29,660.0 Pa.

3 When the pressure of supply water was $12 \mathrm{MPa}$, compared with the pressure distribution with a water pressure of $10 \mathrm{MPa}$, the pressure gradient was relatively uniform and not violent. A negative pressure zone appeared at the outlet of the nozzle, which was similar to the shape of a liquid flow. From the nozzle to the outlet of the ejector barrel, the pressure gradient did not change obviously, and a pressure gradient higher than the surrounding pressure gradient appeared locally. The minimum pressure value in the flow field was $-350,400.0 \mathrm{~Pa}$.

4 When the water supply pressure was $14 \mathrm{MPa}$, the characteristics of the pressure distribution were different from others. The pressure gradient from the inlet of the ejector barrel to the nozzle varied obviously due to the action of injection-induced air suction. Conversely, the pressure gradient from the nozzle to the outlet of the ejector barrel did not. The reasons for the latter phenomenon can be summarized as follows: The spray field under this pres- 


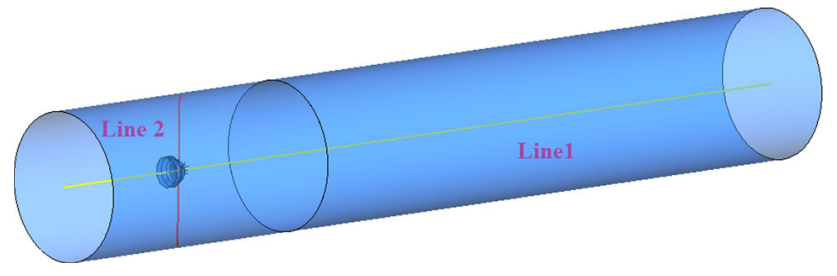

Fig. 14 Physical model of reference line in ejector barrel

sure was less affected by the horizontal airflow, so the droplets have a stronger ability to migrate; while the coefficient characterizing the pressure gradient was inversely proportional to the square of the fluid's migration speed, so the gradient from the nozzle to the outlet of the ejector barrel changed relatively smoothly. Additionally, the minimum pressure value in the flow field was $-227,400.0 \mathrm{~Pa}$.

5 When the pressure of supply water was $16 \mathrm{MPa}$, its pressure distribution was similar to the water pressure of $12 \mathrm{MPa}$, the difference was that the pressure gradient did not change obviously from the nozzle to the outlet of ejector barrel, and the local high pressure decreased. The minimum pressure in the flow field was $-343,200.0 \mathrm{~Pa}$.

In order to analyze pressure changes more intuitively and accurately, two reference lines were established in the five models, as shown in Fig. 14, which were line 1 (the axis of the ejector barrel) and line 2 (which was perpendicular to the axis through the outlet of the nozzle). The pressure changes on line 1 and line 2 at different pressure of supply water are shown in Fig. 15. In (a), the horizontal coordinate $X$ was the position of the upper point on line 1 , where the coordinate of the air inlet was $X=-0.4$, the coordinate of the nozzle's outlet was $X=-0.25$, the coordinate of the outlet of the ejector barrel was $X=0.4$, and the ordinate was the pressure value. In (b), the horizontal coordinate $Y$ represented the position of the point on line 2 , the ordinate was the pressure value, and $Y=0$ represented the midpoint of line 2 . The pressure at each point on line 2 was basically symmetric about the point $Y=0$.

From Fig. 15, the following conclusions were drawn:

1 Under different pressure of supply water, the pressure values at the inlet and outlet ends of the ejector barrel were basically the same. When the pressure of supply water was $8 \mathrm{MPa}$, the pressure of the flow field decreased with the increase in the abscissa. When the pressure of supply water was $10 \mathrm{MPa}$, the pressure decreased first, then increased and finally decreased with the increase in the abscissa.

2 When the pressure of supply water was $12 \mathrm{MPa}, 14 \mathrm{MPa}$, and $16 \mathrm{MPa}$, the pressure from the inlet end of the ejector barrel to the nozzle decreased at different speeds. In the range from the nozzle to the outlet of the ejector barrel, the pressure was generally rising. Generally, when the pressure of supply water was $12 \mathrm{MPa}$ and $16 \mathrm{MPa}$, the pressure drop was larger, and the negative pressure at the outlet of the nozzle was lower.

3 When $-0.06 \leq Y \leq-0.015$, the pressure dropped slowly because it was far from the center of the jet; When $0.015 \leq Y \leq 0$, the pressure dropped rapidly near the center of the jet and reached the minimum at the outlet of the nozzle. In general, the pressure at $Y=0$ was the lowest when the water pressure was $12 \mathrm{MPa}$ and $16 \mathrm{MPa}$. In summary, when the pressure of supply water was $12 \mathrm{MPa}$ and $16 \mathrm{MPa}$, the range of the negative pressure zone in the flow field was large, and the differential pressure was large, which was most conducive to dust removal.

\subsection{Velocity Distribution and Discussion}

The velocity distribution on the central surface of the ejector barrel is shown in Fig. 16 under different pressure of supply water.

It can be observed in Fig. 16 that:

1 The fluid velocity in the two areas of the nozzle and the liquid-gas interface changed drastically, and the fluid velocity distribution in the other positions was more uniform and proceeded in a straight direction. The velocity at the outlet of the nozzle was the highest. At the liquid-gas interface, due to the collision of the fluids, the magnitude and direction of the velocity changed drastically.

2 When the water pressure was $8 \mathrm{MPa}$ and $10 \mathrm{MPa}$, the fluid velocity did not change in a large range, and the whirlpool was basically not formed. When the water pressure reached $12 \mathrm{MPa}, 14 \mathrm{MPa}$, and $16 \mathrm{MPa}$, the fluid velocity at the liquid-gas interface changed sharply, at this time, the fluid from the nozzle was affected by gravity, and part of the water flow moved downward in an oblique direction, which led to the larger fluid velocity below the nozzle, and the pressure relative to the upper part of the nozzle to low, so the airflow moved along the bottom of the nozzle. At the same time, a whirlpool was formed due to the high-speed collision between the liquid-gas two-phase flow.

The fluid velocity changes in line 1 and line 2 as the pressure of supply water changes are shown in Fig. 17.

From Fig. 17, the following conclusions were drawn:

1 When the water pressure was $8 \mathrm{MPa}$ and $10 \mathrm{MPa}$, the velocity on line 1 basically tended to be flat without large fluctuation, and indicated that the fluid velocity of flow field was stable. When the pressure of supply water was $12 \mathrm{MPa}, 14 \mathrm{MPa}$, and $16 \mathrm{MPa}$, within the range from 


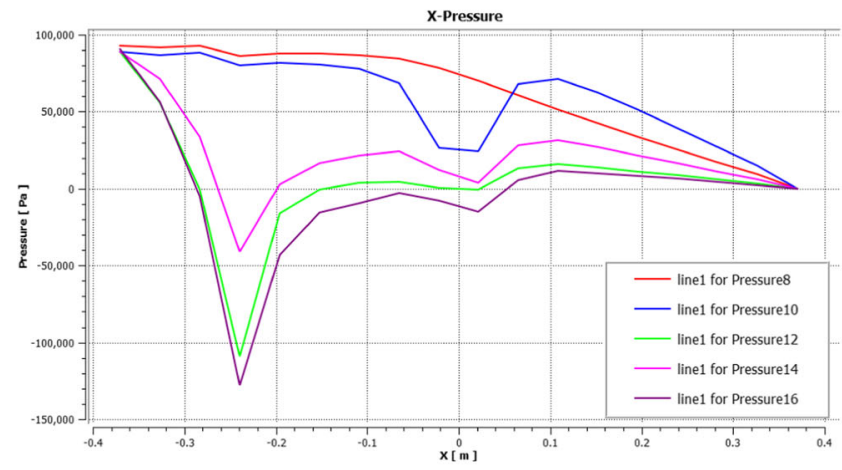

(a) The pressure change on line 1

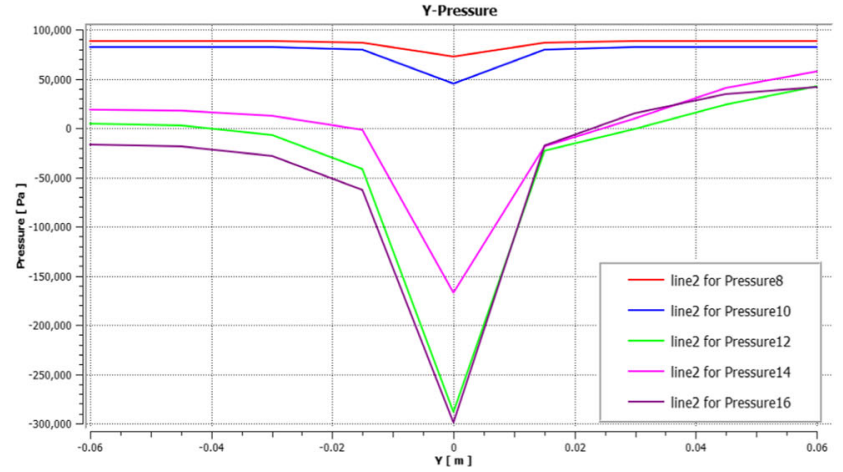

(b) The pressure change on line 2

Fig. 15 The pressure changes on line 1 and line 2 at different pressure of supply water, where a the pressure change on line 1 , $\mathbf{b}$ the pressure change on line 2

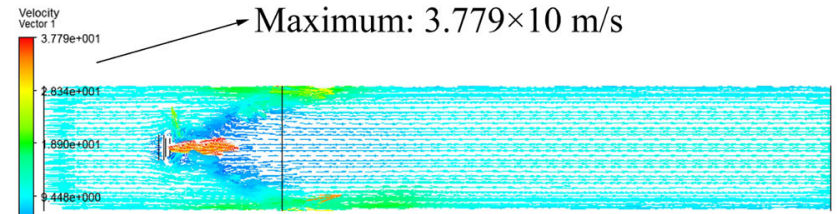

(a) Water pressure: $8 \mathrm{MPa}$

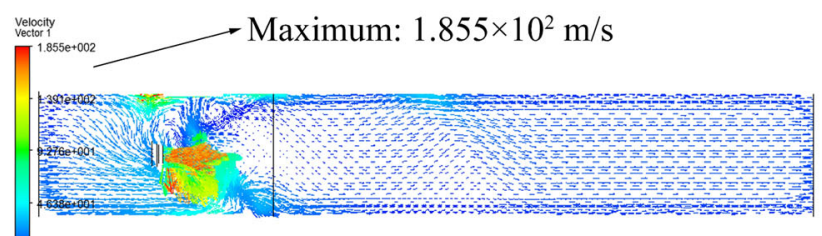

(c) Water pressure: $12 \mathrm{MPa}$



(b) Water pressure: $10 \mathrm{MPa}$



(d) Water pressure: $14 \mathrm{MPa}$

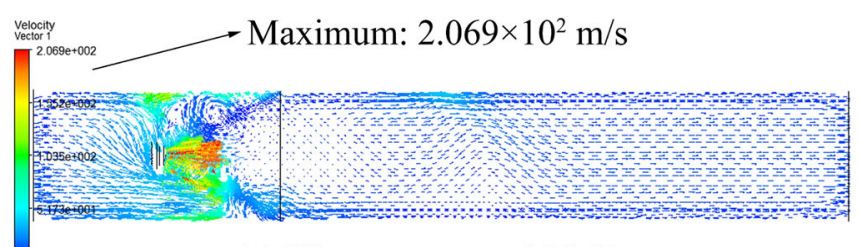

(e) Water pressure: $16 \mathrm{MPa}$

Fig. 16 The velocity distribution on the central surface of the ejector barrel under different pressure of supply water, where a water pressure: $8 \mathrm{MPa}$, b water pressure: $10 \mathrm{MPa}, \mathbf{c}$ water pressure: $12 \mathrm{MPa}$, d water pressure: $14 \mathrm{MPa}$, e water pressure: $16 \mathrm{MPa}$

the airflow inlet to the nozzle, the fluid velocity increased rapidly and reached the maximum at the outlet of the nozzle, then decreased rapidly and finally flattened.

2 When the pressure of supply water was $12 \mathrm{MPa}$, the fluid velocity reached the maximum value at the outlet of the nozzle. The fluid velocity on line 2 fluctuated frequently, with no symmetry and poor regularity. At $Y=-0.06$ and $Y=0.06$, that was, closed to the wall of the tube, the fluid velocity approached 0 . When $-0.06 \leq Y \leq 0$, the maximum velocity appeared on the line with water pressure of $12 \mathrm{MPa}$. When $0 \leq Y \leq 0.06$, the maximum velocity appeared on the line with water pressure of $16 \mathrm{MPa}$. Generally, when the pressure of supply water was $12 \mathrm{MPa}$, the fluid velocity was maximum and the quantity of airflow inhaled per unit time was large in the range near the outlet of the nozzle, which was most conducive to dust removal.

To sum up, from the point of view of pressure distribution, when the pressure of supply water was $12 \mathrm{MPa}$ and $16 \mathrm{MPa}$, the negative pressure area at the nozzle in the flow field was large and the negative pressure value was low. However, when the pressure of supply water was raised from 12 


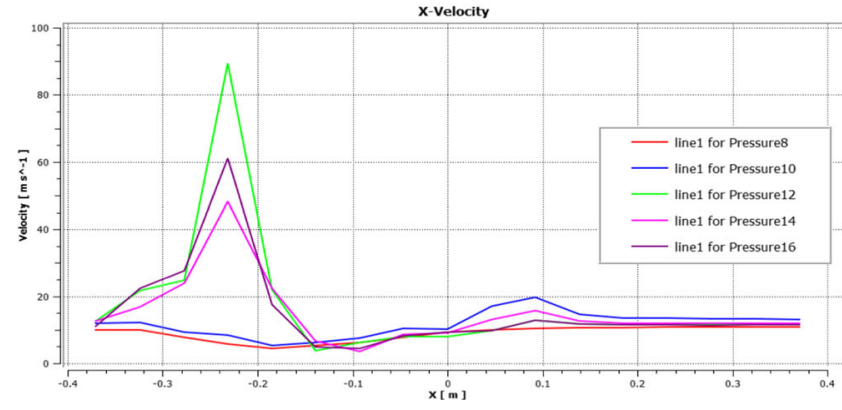

(a) The velocity change on line 1

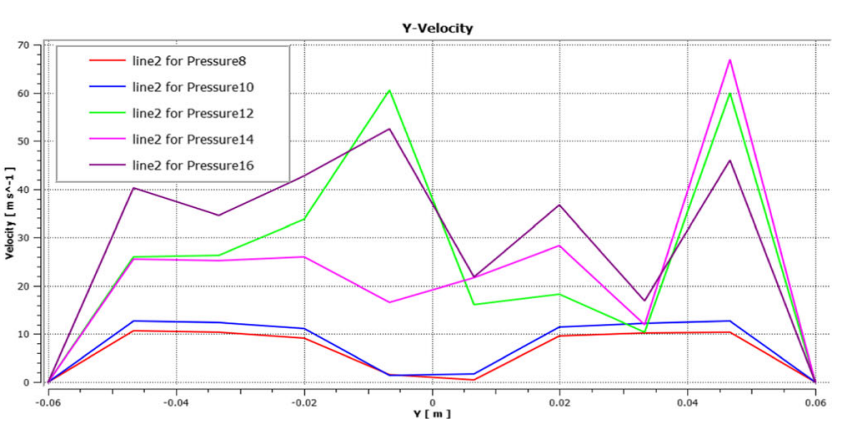

(b) The velocity change on line 2

Fig. 17 The fluid velocity changes in line 1 and line 2, where a the velocity change on line 1, b the velocity change on line 2

to $16 \mathrm{MPa}$, the negative pressure drop was not large, and the requirement for the pump station and pipeline was higher. Therefore, the pressure of supply water $12 \mathrm{MPa}$ was preferred. From the perspective of velocity distribution, when the pressure of supply water was $12 \mathrm{MPa}$, the flow velocity at the nozzle in the flow field was the highest and the entrainment capacity was the strongest. Therefore, the pressure of supply water recommended by the numerical simulation was $12 \mathrm{MPa}$.

\section{Field Tests for Validation}

The engineering significance of studying spray dust removal lies in its application in mining sites. Field tests for coal mine were conducted to verify the correctness and rationality of the laboratory experiment and numerical simulation results in this study. The field test was carried out in 11,091 fully mechanized mining face in Chaohua colliery of Zhengmei group. The coal seam of the working face was black and powdery, and the coal quality was high-quality industrial coal with medium ash, low sulfur, and high calorific value. The thinnest and thickest parts of the coal seam were $3.0 \mathrm{~mm}$ and $22.5 \mathrm{~m}$, respectively, and the average coal thickness of the working face was $13.2 \mathrm{~m}$. The minimum inclination and maximum inclination in the west of the coal seam were $3^{\circ} 18^{\prime}$ and $16^{\circ}$, respectively, and the average inclination of the working face was $8^{\circ} 24^{\prime}$. The maximum wind speed of working face is $3.7 \mathrm{~m} / \mathrm{s}$.

\subsection{Design of Field Test}

The hydraulic support adopted ZF13000/21/40 low-level caving coal hydraulic support and was equipped with double conveyors. A tail beam with a sliding plate was hinged at the rear of the shield beam to loosen the top coal, maintained a coal falling space, and had a continuous coal caving opening. On the fully mechanized mining face, the front-end conveyor was located under the top beam, and the back-end conveyor was located under the shield beam. Considering that the shield beam was close to the coal caving mouth and far from the sidewalk, the ejector precipitator was installed on the shield beam of the low-level caving coal hydraulic support during the field test. Additionally, the dust-laden water generated during the dust removal process could be discharged from the coal mining operation area through the back-end conveyor after the baffle separator. As a result, the wastewater would neither wet the mine tunnel nor affect the normal operations of miners.

The connection of pipeline in the field test is shown in Fig. 18. When the hydraulic support worked, firstly, opened the globe valve, the main manual gate valve and the emulsion pump in order to make the water flowed to the ejector precipitator. Then adjusted the overflow valve until the pressure of the bypass pressure gauge reached operation requirements of the ejector precipitator, at this time, the coal dust sampler was opened. Finally, the water consumption was read on the spot and the coal dust concentration was measured in the mine. The arrangement of coal dust sampling points is shown in Fig. 19, the measuring points were arranged on the upwind side, downwind side, and the pavement, respectively. The waterway control system at the test site is shown in Fig. 20. When the system worked, no matter which end of the working surface started to drive, the ejector precipitator of the moving bracket was always activated simultaneously with the ejector precipitator of the adjacent bracket on the downwind side to give full play to its dedusting effect.

XRB2B(A) type of emulsion pump was used in the test, its rated pressure was $20 \mathrm{MPa}$, rated flow was $80 \mathrm{~L} / \mathrm{min}$, rated speed of the motor was $1470 \mathrm{r} / \mathrm{min}$ and rated power of the motor was $37 \mathrm{~kW}$. The AFQ-20A type of coal dust sampler was used, the sampling flow was $20 \mathrm{~L} / \mathrm{min}$, the negative pressure of air extraction was more than $5000 \mathrm{~Pa}$, the applicable temperature range was from 0 to $35^{\circ} \mathrm{C}$, the applicable relative humidity was less than $95 \%$, and the sampling range was total coal dust and respirable coal dust. The working principle of the coal dust sampler is shown in Fig. 21. Before sampling, selected a suitable pre-capturer, installed the cleaned filter 
Fig. 18 The connection of pipeline in the field test

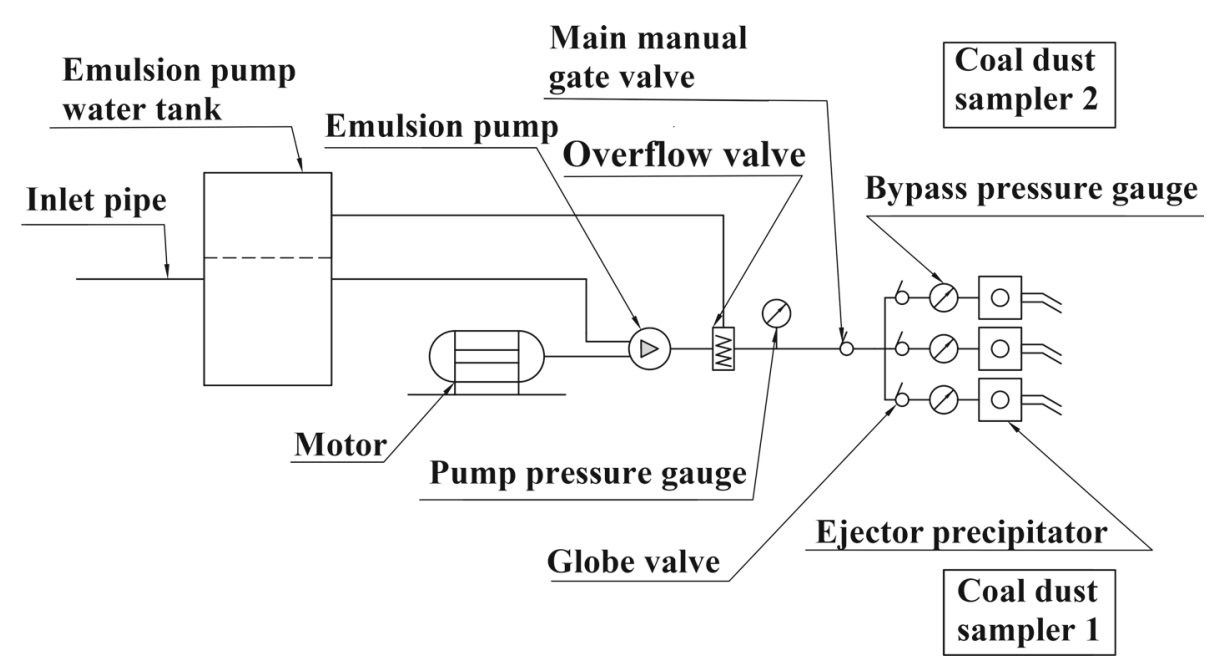

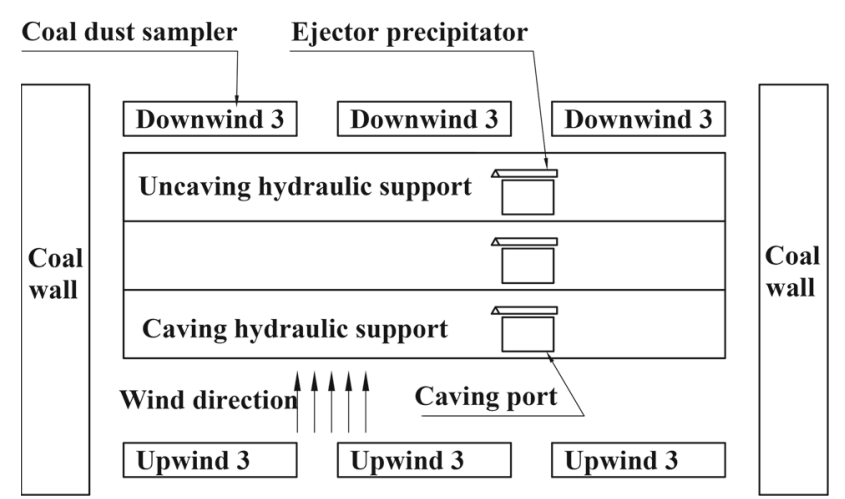

Fig. 19 The arrangement of coal dust sampling points

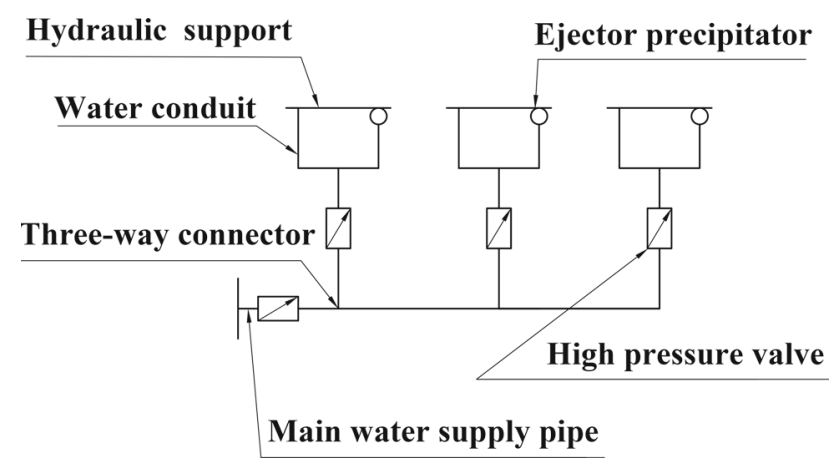

Fig. 20 The waterway control system

membrane weighed, screwed it on the sampler sampling connection base, and then set the required sampling time through the preset device on the sampler. When sampling was started, the power switch was turned on. After pressed the work button, the motor ran immediately, and the suction pump was driven to start working. The flow adjustment indicator was randomly adjusted to make the flow meter display reached the specified value. After the dust-laden airflow was drawn into the pre-capturer, coal dust was trapped on the filter membrane

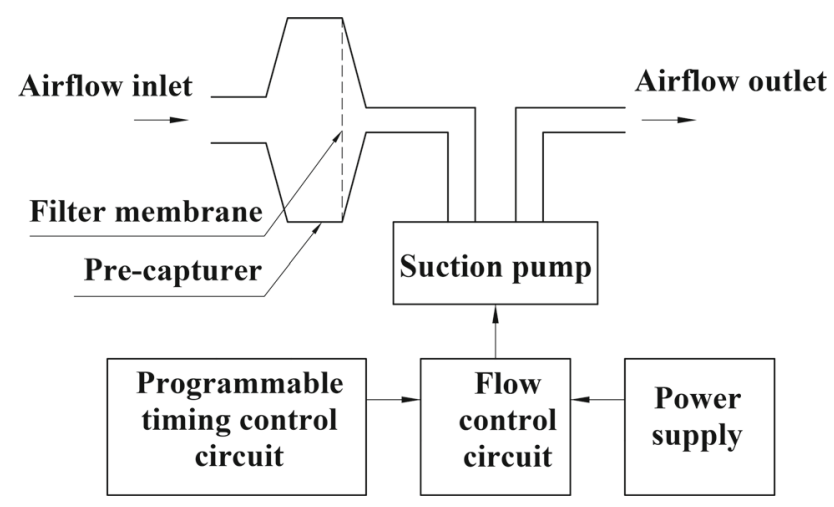

Fig. 21 The working principle of the coal dust sampler

and gradually accumulated. When the sampling preset time expired, the motor power was automatically disconnected and the sampling stopped immediately. At this time, the coal dust sample was taken out for weighing, and the coal dust concentration value can be obtained after calculation.

\subsection{Results and Discussion}

\subsubsection{Accuracy Test of Numerical Simulation Results}

The liquid-gas ratio of numerical simulation and field test is shown in Table 4. There was an error between the data obtained from numerical simulation and field test. The error was calculated as follows:

$\omega=\frac{\sum_{i=j=1}^{3}\left|\zeta_{i}-\zeta_{j}\right|}{\sum_{j=1}^{3} \zeta_{j}} \times 100 \%$, 
Table 4 The results of the numerical simulation and field measurement

\begin{tabular}{|c|c|c|c|c|c|c|}
\hline \multirow[t]{2}{*}{ Water pressure } & \multicolumn{2}{|l|}{ Numerical simulation } & \multicolumn{2}{|l|}{ Field measurement } & \multirow[t]{2}{*}{$\zeta_{i}$} & \multirow[t]{2}{*}{$\zeta_{j}$} \\
\hline & Water consumption $(\mathrm{L} / \mathrm{s})$ & Airflow volume $\left(\mathrm{m}^{3} / \mathrm{s}\right)$ & Water consumption $(\mathrm{L} / \mathrm{s})$ & Airflow volume $\left(\mathrm{m}^{3} / \mathrm{s}\right)$ & & \\
\hline 10 & 0.064 & 0.191 & 0.064 & 0.160 & $1: 2984$ & $1: 2494$ \\
\hline 12 & 0.089 & 0.190 & 0.089 & 0.175 & $1: 2135$ & $1: 1972$ \\
\hline 14 & 0.118 & 0.195 & 0.118 & 0.212 & $1: 1653$ & $1: 1793$ \\
\hline
\end{tabular}

Table 5 The test results of the coal dust removal ratio

\begin{tabular}{|c|c|c|c|c|c|c|}
\hline \multirow[t]{2}{*}{ Sampling position } & \multicolumn{2}{|c|}{$\begin{array}{l}\text { Coal dust concentration on the upwind } \\
\text { side }\left(\mathrm{mg} / \mathrm{m}^{3}\right)\end{array}$} & \multicolumn{2}{|c|}{$\begin{array}{l}\text { Coal dust concentration on the } \\
\text { downwind side }\left(\mathrm{mg} / \mathrm{m}^{3}\right)\end{array}$} & \multicolumn{2}{|c|}{ Removal ratio of coal dust (\%) } \\
\hline & The total coal dust & $\begin{array}{l}\text { The respirable } \\
\text { coal dust }\end{array}$ & The total coal dust & $\begin{array}{l}\text { The respirable } \\
\text { coal dust }\end{array}$ & The total coal dust & $\begin{array}{l}\text { The respirable } \\
\text { coal dust }\end{array}$ \\
\hline 1 & 198.8 & 113.8 & 98.6 & 57.4 & 50.4 & 49.6 \\
\hline 2 & 119.8 & 57.5 & 46.7 & 24.2 & 61.0 & 57.9 \\
\hline 3 & 585.0 & 390.0 & 61.3 & 35.0 & 89.5 & 91.0 \\
\hline Average value & & & & & 67.0 & 66.2 \\
\hline
\end{tabular}

where $\omega$ denotes the liquid-gas ratio error; $\zeta_{i}$ denotes the liquid-gas ratio of numerical simulation; $\zeta_{j}$ denotes the liquid-gas ratio of field measurements.

The calculated error of liquid-gas ratio was only 3.9\%. Considering that there were relative differences between the simulation environment and the real situation, and the physical model had been simplified before the simulation, so the results of numerical simulation were valid, and the pressure and velocity distribution of the liquid-gas two-phase flow field in the ejector barrel were described reasonably by the physical model. In conclusion, the analysis results of Fluent were in line with the engineering practice, and the model was relatively accurate.

\subsubsection{Testing of Dust Removal Efficiency}

The measurement results of three ejector precipitator opened at the same time are shown in Table 5. The calculation formula of dust removal ratio in Table 5 is as follows:

$\eta=\frac{C_{1}-C_{2}}{C_{2}} \times 100 \%$

where $\eta$ denotes the dust removal ratio; $C_{1}$ denotes the coal dust concentration on the upwind side, $\mathrm{mg} / \mathrm{m}^{3} ; C_{2}$ denotes the coal dust concentration on downwind side, $\mathrm{mg} / \mathrm{m}^{3}$.

In general, in the absence of the use of an ejector precipitator, owing to the movement of airflow in the area, coal dust was mainly concentrated on the downwind side. However, due to the use of the designed ejector precipitator, the coal dust concentration on the downwind side was significantly reduced compared to the upwind side.
As can be known from Table 5, the average removal ratios of the total coal dust and the respirable coal dust were $67.0 \%$ and $66.2 \%$, respectively, the removal ratios of the total coal dust and the respirable coal dust were $89.5 \%$ and $91.0 \%$, respectively, at the sampling locations with the highest concentration of coal dust. This indicated that the dust removal effect was better when the coal dust concentration was high, so the designed ejector precipitator was suitable for a fully mechanized mining face with a high concentration of coal dust.

\section{Conclusion}

The effects of nozzles' structure parameters and water supply pressure on the performance of an ejector precipitator are studied based on laboratory experiments and numerical simulations, and field tests are performed to verify results of numerical simulations and the dust removal ratio of the ejector precipitator. The following primary conclusions can be obtained from this study:

1 The structural parameters of nozzles and water supply pressure have a direct influence on the performance of the ejector precipitator. The structural parameters of nozzles recommended by experiments are as follows: $D_{0}=$ $1.5 \mathrm{~mm}, T=1.0 \mathrm{~mm}, d=1.0 \mathrm{~mm}, L_{1}=1.2 \mathrm{~mm}$, and $L_{2}$ $=1.8 \mathrm{~mm}$; the shape of the spiral grooves is rectangular, and the number of the spiral grooves is 3 . Besides, the water supply pressure recommended by numerical simulations is $12 \mathrm{MPa}$. It is worth noting that the pressure loss of the pipeline is ignored during the numerical sim- 
ulation, but the measurement of liquid-gas ratio on site shows that the numerical calculation results can still meet the engineering requirements.

2 According to field test results, after the recommended nozzle model and water supply pressure are used, the removal ratios of total coal dust and respirable coal dust at the measuring point with the highest concentration are as high as $89.5 \%$ and $91.0 \%$, respectively, suggesting that the designed ejector precipitator is suitable for a fully mechanized mining face with high coal dust concentration, and the coal dust removal effect is better. It should be noted that the air humidity near the hydraulic support on site is close to $100 \%$, which leads to excess moisture in the filter film of the dust sample. Consequently, the measured values of coal dust removal ratio in field tests are slightly lower.

3 The inner-rotation nozzle built in the ejector precipitator proposed can provide more the turbulent kinetic energy of the liquid flow by relying on the rotation of the core body, which increases the velocity of the liquid flow micelles. Thusly, it has better atomization characteristics and higher atomization efficiency compared with the coal caving spray, the conventional internal spray of coal cutter, etc. Moreover, compared with the external spray of coal cutter and the original hydraulic support spray, the proposed ejector precipitator limits the spray to a limited space, i.e., the coal dust is sealed in the ejector barrel by spraying, which prevents availably the coal dust from escaping into the operating areas and sidewalks.

4 The ejector precipitator designed in this study is mainly aimed at the coal dust generated by the movement between the hydraulic support, but the spray cannot completely cover the dust source near the hydraulic support. Thusly, the focus of the follow-up work will be to optimize the arrangement of ejector precipitator according to the dustproducing environment of multi-dust source in a fully mechanized mining face, and to achieve full coverage of dust sources as much as possible, thereby further achieving the efficient control of coal dust at separate sources.

5 Based on spray dust removal technology, future research will develop a complete set of collaborative prevention and control equipment that combines dry and wet mixed dust removal, intelligent regulation, and miniaturization, and then realize the transformation from a single dust control technology to a variety of composite technologies.

Funding This work was financially supported by the National Training Program of Innovation and Entrepreneurship for Undergraduates (Grant No. 202011413034), the Fundamental Research Funds for the Central Universities (Grant No. 2020YJSJD06), the Cross Training Program of High-Level Talents in Beijing University (Grant No. 2019114132316), the Teaching Reform Project of China University of Mining and Technology-Beijing (Grant Nos. J200518, J20ZD17).

\section{Compliance with Ethical Standards}

Conflict of interest The authors declare no conflict of interest.

Availability of Data and Material My co-authors and I have confirmed that all data and materials support their published claims and comply with field standards.

Open Access This article is licensed under a Creative Commons Attribution 4.0 International License, which permits use, sharing, adaptation, distribution and reproduction in any medium or format, as long as you give appropriate credit to the original author(s) and the source, provide a link to the Creative Commons licence, and indicate if changes were made. The images or other third party material in this article are included in the article's Creative Commons licence, unless indicated otherwise in a credit line to the material. If material is not included in the article's Creative Commons licence and your intended use is not permitted by statutory regulation or exceeds the permitted use, you will need to obtain permission directly from the copyright holder. To view a copy of this licence, visit http://creativecomm ons.org/licenses/by/4.0/.

\section{References}

1. Zhang, H.H.; Nie, W.; Wang, H.K.; Bao, Q.; Jin, H.; Liu, Y.H.: Preparation and experimental dust suppression performance characterization of a novel guar gum-modification-based environmentally-friendly degradable dust suppressant. Powder Technol. 339, 314-325 (2018)

2. Elliott, R.J.R.; Sun, P.Y.; Zhu, T.: The direct and indirect effect of urbanization on energy intensity: a province-level study for China. Energy 123, 677-692 (2017)

3. Jin, H.; Nie, W.; Zhang, Y.S.; Wang, H.K.; Zhang, H.H.; Bao, Q.; Yan, J.Y.: Development of environmental friendly dust suppressant based on the modification of soybean protein isolate. Processes 7(3), 17 (2019)

4. Zhou, G.; Zhang, Q.; Bai, R.N.; Fan, T.; Wang, G.: The diffusion behavior law of respirable dust at fully mechanized caving face in coal mine: CFD numerical simulation and engineering application. Process Saf. Environ. Prot. 106, 117-128 (2017)

5. Wang, P.F.; Tan, X.H.; Zhang, L.Y.; Li, Y.J.; Liu, R.H.: Influence of particle diameter on the wettability of coal dust and the dust suppression efficiency via spraying. Process Saf. Environ. Prot. 132, 189-199 (2019)

6. Wang, J.Y.; Zhou, G.; Wei, X.; Wang, S.C.: Experimental characterization of multi-nozzle atomization interference for dust reduction between hydraulic supports at a fully mechanized coal mining face. Environ. Sci. Pollut. Res. 26(10), 10023-10036 (2019)

7. Nie, W.; Wei, W.L.; Cai, P.; Liu, Z.Q.; Liu, Q.; Ma, H.; Liu, H.J.: Simulation experiments on the controllability of dust diffusion by means of multi-radial vortex airflow. Adv. Powder Technol. 29(3), 835-847 (2018)

8. Xu, C.W.; Nie, W.; Liu, Z.Q.; Peng, H.T.; Yang, S.B.; Liu, Q.: Multi-factor numerical simulation study on spray dust suppression device in coal mining process. Energy 182, 544-558 (2019)

9. Wang, Z.W.; Ren, T.: Investigation of airflow and respirable dust flow behaviour above an underground bin. Powder Technol. 250, 103-114 (2013)

10. Yu, H.M.; Cheng, W.M.; Wu, L.R.; Wang, H.; Xie, Y.: Mechanisms of dust diffuse pollution under forced-exhaust ventilation in fullymechanized excavation faces by CFD-DEM. Powder Technol. 317, 31-47 (2017) 
11. Wang, Q.G.; Wang, D.M.; Wang, H.T.; Han, F.W.; Zhu, X.L.; Tang, Y.; Si, W.B.: Optimization and implementation of a foam system to suppress dust in coal mine excavation face. Process Saf. Environ. Prot. 96, 184-190 (2015)

12. Xi, Z.L.; Jiang, M.M.; Yang, J.J.; Tu, X.: Experimental study on advantages of foam-sol in coal dust control. Process Saf. Environ. Prot. 92(6), 637-644 (2014)

13. Wang, Q.G.; Wang, D.M.; Wang, H.T.; Liu, J.N.; He, F.: Experimental study and implementation of a novel internal foam spraying system for roadheaders. Tunn. Undergr. Space Technol. 59, 127-133 (2016)

14. Wang, H.T.; Wang, D.M.; Tang, Y.; He, X.X.: Effects of geometric parameters on air suction characteristics of a new jet-type foam generator for mine dust suppression. Arab. J. Sci. Eng. 43(3), 1445-1454 (2018)

15. Tessum, M.W.; Raynor, P.C.: Effects of spray surfactant and particle charge on respirable coal dust capture. Saf. Health Work 8(3), 296-305 (2017)

16. Wang, Y.C.; Luo, G.; Geng, F.; Li, Y.B.; Li, Y.L.: Numerical study on dust movement and dust distribution for hybrid ventilation system in a laneway of coal mine. J. Loss Prev. Process Ind. 36, 146-157 (2015)

17. Li, Y.J.; Wang, P.F.; Liu, R.H.; Jiang, Y.D.; Han, H.: Determination of the optimal axial-to-radial flow ratio of the wall-mounted swirling ventilation in fully mechanized excavation face. Powder Technol. 360, 890-910 (2020)

18. Gao, G.J.; Wang, C.J.; Kou, Z.M.: Experimental studies on the spraying pattern of a swirl nozzle for coal dust control. Appl. Sci. 8(10), 14 (2018)

19. Kou, B.F.; Liu, Q.Z.; Cao, S.C.; Hu, X.H.; Li, Y.F.; Wang, Y.R.; Zhao, B.H.: Experimental investigation on atomization and collecting efficiency of wind-spray dust controller and its parameters optimization. J. Cent. South Univ. 22(11), 4213-4218 (2015)

20. Nie, W.; Ma, X.; Cheng, W.M.; Liu, Y.H.; Xin, L.; Peng, H.T.; Wei, W.L.: A novel spraying/negative-pressure secondary dust suppression device used in fully mechanized mining face: a case study. Process Saf. Environ. Prot. 103, 126-135 (2016)

21. Cheng, W.M.; Ma, Y.Y.; Yang, J.L.; Sun, B.: Effects of atomization parameters of dust removal nozzles on the de-dusting results for different dust sources. Int. J. Min. Sci. Technol. 26(6), 1025-1032 (2016)

22. Sun, B.; Cheng, W.M.; Wang, J.Y.; Wang, H.; Ma, Y.Y.: Development of Venturi negative-pressure secondary dedust device and application of local spray closure technique. Adv. Powder Technol. 30(1), 42-54 (2019)

23. Zhou, Q.; Qin, B.T.; Wang, F.; Wang, H.T.; Hou, J.; Wang, Z.R.: Effects of droplet formation patterns on the atomization characteristics of a dust removal spray in a coal cutter. Powder Technol. 344, 570-580 (2019)

24. Wang, H.T.; Wu, J.L.; Du, Y.H.; Wang, D.M.: Investigation on the atomization characteristics of a solid-cone spray for dust reduction at low and medium pressures. Adv. Powder Technol. 30(5), 903-910 (2019)

25. Wang, P.F.; Shi, Y.J.; Zhang, L.Y.; Li, Y.J.: Effect of structural parameters on atomization characteristics and dust reduction performance of internal-mixing air-assisted atomizer nozzle. Process Saf. Environ. Prot. 128, 316-328 (2019)

26. Nie, W.; Liu, Y.H.; Wang, H.; Wei, W.L.; Peng, H.T.; Cai, P.; Hua, Y.; Jin, H.: The development and testing of a novel externalspraying injection dedusting device for the heading machine in a fully-mechanized excavation face. Process Saf. Environ. Prot. 109, 716-731 (2017)

27. Yu, H.M.; Cheng, W.M.; Peng, H.T.; Xie, Y.: An investigation of the nozzle's atomization dust suppression rules in a fully-mechanized excavation face based on the airflow-droplet-dust three-phase coupling model. Adv. Powder Technol. 29(4), 941-956 (2018)
28. Peng, H.T.; Nie, W.; Cai, P.; Liu, Q.; Liu, Z.Q.; Yang, S.B.: Development of a novel wind-assisted centralized spraying dedusting device for dust suppression in a fully mechanized mining face. Environ. Sci. Pollut. Res. 26(4), 3292-3307 (2019)

29. Zhou, G.; Zhang, Q.T.; Hu, Y.Y.; Gao, D.H.; Wang, S.C.; Sun, B.: Dust removal effect of negatively-pressured spraying collector for advancing support in fully mechanized coal mining face: numerical simulation and engineering application. Tunn. Undergr. Space Technol. 95, 14 (2020)

30. Liu, X.F.; Chang, P.; Wang, E.Y.; Zhang, Z.G.; Yang, S.: Numerical study of the respirable coal dust removal performance of a vortex ventilation system at an excavation face. Energies 11(9), 18 (2018)

31. Zhai, G.D.; Li, Y.Z.; Li, Z.; Cheng, Q.Z.: Optimization and design on negative-pressure dust remover at coal outlet of hydraulic support in coal mine. Saf. Coal Mines 48(06), 94-96+100 (2017)

32. Mutharasu, L.C.; Kalaga, D.V.; Sathe, M.; Turney, D.E.; Griffin, D.; Li, X.; Kawaji, M.; Nandakumar, K.; Joshi, J.B.: Experimental study and CFD simulation of the multiphase flow conditions encountered in a novel down-flow bubble column. Chem. Eng. J. 350, 507-522 (2018)

33. Ren, T.; Karekal, S.; Cooper, G.; Wang, Z.; Plush B.: Design and field trials of water-mist based venturi systems for dust mitigation on longwall faces. In: 2013 13th Coal Operators' Conference, pp. 209-220

34. Urbán, A.; Zaremba, M.; Malý, M.; Józsa, V.; Jedelský, J.: Droplet dynamics and size characterization of high-velocity air-blast atomization. Int. J. Multiph. Flow 95, 1-11 (2017)

35. Yin, W.J.; Zhou, G.; Gao, D.H.: Simulation analysis and engineering application of distribution characteristics about multi-stage atomization field for cutting dust in fully mechanized mining face. Adv. Powder Technol. 30(11), 2600-2615 (2019)

36. Zhai, G.D.; Ren, C.; Tong, W.: Design and optimization of innerrotation nozzle in negative pressure duster. Adv. Mech. Eng. 11(10), $1-25$ (2019)

37. Chai, H.L.; Geng, F.; Wu, X.; Yang, Y.Y.; Luo, G.; Zhang, T.T.: Numerical investigation of gas-liquid two-phase flow in a quench chamber of an entrained flow gasifier. Int. J. Hydrog. Energy 42(9), 5873-5885 (2017)

38. Khopkar, A.R.; Rammohan, A.R.; Ranade, V.V.; Dudukovic, M.P.: Gas-liquid flow generated by a Rushton turbine in stirred vessel: CARPT/CT measurements and CFD simulations. Chem. Eng. Sci. 60(8-9), 2215-2229 (2005)

39. Yang, S.B.; Nie, W.; Lv, S.S.; Li, Z.Q.; Peng, H.T.; Ma, X.; Cai, P.; Xu, C.W.: Effects of spraying pressure and installation angle of nozzles on atomization characteristics of external spraying system at a fully-mechanized mining face. Powder Technol. 343, 754-764 (2019)

40. Zhang, Q.; Zhou, G.; Qian, X.M.; Yuan, M.Q.; Sun, Y.L.; Wang, D.: Diffuse pollution characteristics of respirable dust in fullymechanized mining face under various velocities based on CFD investigation. J. Clean. Prod. 184, 239-250 (2018)

41. Hua, Y.; Nie, W.; Cai, P.; Liu, Y.H.; Peng, H.T.; Liu, Q.: Pattern characterization concerning spatial and temporal evolution of dust pollution associated with two typical ventilation methods at fully mechanized excavation faces in rock tunnels. Powder Technol. 334, 117-131 (2018)

42. Shakeel, M.R.; Sanusi, Y.S.; Mokheimer, E.M.A.: Numerical modeling of oxy-methane combustion in a model gas turbine combustor. Appl. Energy 228, 68-81 (2018)

43. Liu, Q.; Nie, W.; Hua, Y.; Peng, H.T.; Liu, Z.Q.: The effects of the installation position of a multi-radial swirling air-curtain generator on dust diffusion and pollution rules in a fully-mechanized excavation face: a case study. Powder Technol. 329, 371-385 (2018)

44. Gao, H.W.; Stenstrom, M.K.: Evaluation of three turbulence models in predicting the steady state hydrodynamics of a secondary sedimentation tank. Water Res. 143, 445-456 (2018) 
45. Sun, B.; Cheng, W.M.; Wang, J.Y.; Wang, H.: Effects of turbulent airflow from coal cutting on pollution characteristics of coal dust in fully-mechanized mining face: a case study. J. Clean. Prod. 201, 308-324 (2018)

46. Wang, P.; Shen, S.; Zhou, L.; Liu, D.Y.: Turbulent aggregation and deposition mechanism of respirable dust pollutants under wet dedusting using a two-fluid model with the population balance method. Int. J. Environ. Res. Public Health 16(18), 20 (2019)

47. Li, Y.J.; Wang, P.F.; Liu, R.H.; Gao, R.Z.: Optimization of structural parameters and installation position of the wall-mounted air cylinder in the fully mechanized excavation face based on CFD and orthogonal design. Process Saf. Environ. Prot. 130, 344-358 (2019)
48. Liu, Z.Q.; Nie, W.; Peng, H.T.; Yang, S.B.; Chen, D.W.; Liu, Q.: The effects of the spraying pressure and nozzle orifice diameter on the atomizing rules and dust suppression performances of an external spraying system in a fully-mechanized excavation face. Powder Technol. 350, 62-80 (2019) 